\title{
Soziolinguistische Perspektiven auf Praktiken des Semiotic Landscaping in Zeiten der Coronavirus-Pandemie. Ein Stadt-Land-Vergleich*
}

\author{
Gertrud Reershemius (Birmingham) und Evelyn Ziegler (Duisburg-Essen)
}

\begin{abstract}
The Covid-19 pandemic has left an impact on the semiotic landscapes of both rural and urban environments. The present study analyses two corpora of signs which emerged as a direct result of the pandemic in the rural environment of Krummhörn, a municipality in northern Germany, and in the city of Essen (Ruhr Metropolis) between March and July 2020. In addition to regulatory and informative signage, the data revealed a high proportion of affective signs which were displayed mainly by individuals around private homes, intended as boosters of collective moral in times of crisis. The analysis shows that slightly different semiotic strategies were applied when comparing a rural with an urban environment.
\end{abstract}

\section{$1 \quad$ Fragestellung und theoretische Einbettung}

„Die Pandemie hat aus Deutschland einen Schulhof gemacht. Überall gibt es Regeln“, so kommentierte Robert Hoffmann in der Zeit-Online Ausgabe vom 11. November 2020 die Beschränkungen der Bewegungsfreiheit im öffentlichen Raum, die im Rahmen der Bekämpfung von COVID-19 verordnet wurden. Verhaltenspflichten wie Abstand halten (etwa auf dem Weg zur Arbeit, zur Schule, beim Einkaufen oder bei Freizeitaktivitäten), Hygiene beachten (z. B. beim Husten und Niesen) und Alltagsmaske tragen bestimmen nun unseren Aufenthalt im öffentlichen Raum, in einzelnen Einrichtungen und Betrieben, z. B. Bildungs- und Kultureinrichtungen, Arztpraxen, Supermärkten, bei Friseuren, in Restaurants und Cafés. Hinweisschilder zu Eingängen und Ausgängen, Bodenaufkleber als Abstandshalter, Aushänge zur Maskenpflicht und vieles andere mehr erinnern uns an diese Regeln. Die visuellen Informationsmittel zur Einhaltung dieser neuen Bestimmungen und Vorgaben oder anderer mit Covid-19 in Zusammenhang stehenden Maßnahmen (z. B. Schließung öffentlicher Aufenthaltsräume wie Parks, Spielplätze und Schwimmbäder) haben nicht nur die Nutzungsbedingungen und sozialen Interaktionen, sondern auch die Semiotik des öffentlichen Raums verändert und werden sie auch weiterhin verändern, sei es durch eine effizientere und wirkungsvollere Gestaltung der Hinweise zu den Verhaltenspflichten und Anordnungen, sei es durch die öffentlich sichtbare Kritik an den Abstands- und Hygieneregeln oder durch Solidaritätsbekundungen und Durchhalteparolen, in

\footnotetext{
* Wir bedanken uns bei Ulrich Schmitz (Duisburg-Essen) und Wolfgang Imo (Hamburg) für ihre hilfreichen Kommentare und Anregungen.
} 
denen sich aktuelle gesellschaftliche Positionierungen zu den Maßnahmen spiegeln. Zusammen konstituieren diese Diskurse als informative, regulative und affektiv-affirmative Zeichen und Gegendiskurse als opponierende und aversive Zeichen die Pandemie bedingte semiotische Zeichenhaftigkeit des öffentlichen Raums. ${ }^{1}$

Die Untersuchung von Zeichen im öffentlichen Raum ist Gegenstand der Semiotic-LandscapeForschung. Ziel der Semiotic-Landscape-Forschung ist es, die sprachlich und nicht-sprachlich verfassten Zeichen im öffentlichen Raum in einer integrierten Analyse in ihrem gesellschaftlichen Kontext zu betrachten, i. e. das ,interplay between language, visual discourse, and the spatial practices and dimensions of culture, especially the textual mediation or discursive construction of place“ (Jaworski/Thurlow 2010: 1) zu untersuchen. Das bedeutet, dass Räume nicht als immer schon gegeben, sondern als sozial konstruiert und damit veränderbar aufgefasst werden. Entsprechend gilt: Der „Raum [ist] ein Ort, mit dem man etwas macht“ (de Certeau 1988/2006: 345). Der Raum als Ergebnis sozialer und sprachlich-kommunikativer Handlungen spiegelt damit die gesellschaftlichen, kulturellen und politischen Strukturen, die in seine semiotic landscapes eingeschrieben sind (cf. Blommaert 2013: 3). Die Zeichen im öffentlichen Raum stellen somit die Spuren sozialen Handelns und gesellschaftlicher Beziehungen dar. Wie Löw (2001: 1) feststellt: Die „Entstehung des Raums [ist] ein soziales Phänomen“(Löw 2001: 263f.), i. e. aber auch, dass es zwischen Raum und Raumnutzern eine Wechselwirkung gibt. Nach diesem Raumverständnis gilt: „Der Ort hat das Gepräge der Gruppe erhalten und umgekehrt.“(Halbwachs 1991: 130 zitiert nach Schroer 2009: 141).

Für die Herstellung, Aneignung und Bedeutung von Räumen spielen verschiedene Faktoren eine Rolle, darunter physikalische, architektonische, städtebauliche, soziale und historische, die unterschiedliche Formen der Nutzung und des Handelns ermöglichen bzw. ausschließen oder verbieten. Schubert (1999: 21) schlägt in diesem Zusammenhang eine Typologie vor, die verschiedene „Raumsituationen“ (a. a. O.) umfasst: Konsumorte, Verkehrsflächen und -wege (Fahrwege, Radwege, Bürgersteige und Fußwege), lokale Räume des Wohnumfeldes (z. B. Spielplätze, Bänke), Räume für Öffentlichkeit (z. B. Park, Museum, Schwimmbad), aufgegebene Flächen (Brachen), halböffentliche Übergangsbereiche (z. B. Balkone, Terrassen, Zufahrten) und Mischformen zwischen öffentlichen und privaten Räumen (z. B. Bahnhofshallen, bei denen öffentlicher Verkehrsraum und Einkaufs- und Gastronomieflächen, die jemandem gehören, verschmelzen). Diese Typologie zeigt, dass der öffentliche Raum kein einheitlicher Raum ist, sondern sich in verschiedene Räume auffächert. Dieser auf Teilräume fokussierten Herangehensweise steht in der Linguistic- bzw. Semiotic-Landscape-Forschung eine Auffassung gegenüber, die den öffentlichen Raum als Bühne konzeptualisiert und mit Goffman (1959/2003) in eine „Vorderbühne“ und „Hinterbühne“ teilt bzw. zwischen „frontstage“ und „backstage“ unterscheidet (Scollon/Scollon 2003: 21), wobei die Hinterbühne als der private Bereich, die Vorderbühne als der öffentliche Bereich definiert werden. Für die Vorderbühne schlagen Scollon/Scollon (ibd.) eine Differenzierung in „exhibit/display spaces“ (z. B. Ausstellungsflächen), „passage spaces“ (z. B. Boulevards, Treppen), ,special use spaces“ (z. B. Raucher-Bereiche)

\footnotetext{
${ }^{1}$ Damit schließt sich unsere Definition an die von Androutsopoulos an: „Die Sprachlandschaft der Pandemie besteht aus allen sprachlichen Zeichen und ihren Trägerflächen, die Wissen von der Pandemie und von den Praktiken ihrer Bekämpfung aufgreifen und dadurch die Pandemie als öffentlichen Zustand diskursiv konstituieren.“ (Androutsopoulos 2020: 294).
} 
und ,secure spaces“ (z. B. Weihnachtsmärkte, die durch Betonpoller gesichert sind) vor, wobei in dieser Typologie der öffentliche Raum gegenüber dem privaten Raum priorisiert wird, erkennbar daran, dass eine Differenzierung der Hinterbühne im Modell von Scollon/Scollon (ibd.) fehlt. Mit Blick auf unsere Untersuchungen stellt sich allerdings die Frage, ob eine solche Differenzierung den empirisch beobachtbaren Praktiken des semiotic landscaping tatsächlich gerecht wird. Denn so wie sich eine zunehmende Privatisierung des öffentlichen Raums beobachten lässt, erkennbar z. B. an Verhaltensweisen wie Smartphonenutzung in der Öffentlichkeit, so lässt sich auch beobachten, dass der private Raum umdefiniert wird, indem er z. B. für Aktivitäten wie Balkonkonzerte oder sichtbaren Protest wie Friedensfahnen an Fenstern genutzt wird. ${ }^{2}$ Die Funktionen mischen sich, eine „Entdifferenzierung von öffentlicher und privater Sphäre“ ist die Folge (cf. Siebel 2015: 66).

Öffentliche Räume als Interaktionsräume lassen sich auch danach differenzieren bzw. betrachten, ob sie als städtische oder ländliche Räume in spezifischer Weise geprägt sind. Aus der Perspektive der Semiotic-Landscape-Forschung schlägt Muth (2015) vor, zwischen einer ,,cityscape“ und einer ,ruralscape“ zu unterschieden. In diesem Zusammenhang stellt Auer (2010) fest:

Es scheint etwa nicht weiter erklärungsbedürftig, dass in ländlichen Regionen weniger Schriftzeichen zu sehen sind als in städtischen. Selbst in alten, stark vom Menschen geformten, aber dennoch ruralen Kulturlandschaften wird der Raum lediglich durch Wege, Landmarken und manchmal auch nicht-sprachliche Zeichen („Steinmännchen“; cf. Schmaucks 2002) strukturiert. Das deutet bereits auf eine erste wesentliche Eigenschaft der Kommunikation durch öffentliche, ortsgebundene Schrift hin: sie macht vor allem solche Räume les- und damit nutzbar, die nicht durch das routinemäßige Zusammenleben Ortskundiger gekennzeichnet sind.

(Auer 2010: 275)

Dies ist jedoch in gewisser Weise eine idealisierende Darstellung vom sozialen Miteinander und damit von Kommunikation in ländlichen Räumen: Wer heutzutage auf dem Land lebt, ist nicht notwendigerweise ortskundig. Neu Zugezogene oder Touristen zum Beispiel sind durchaus auf lesbare Räume angewiesen. Die diesem Artikel zugrunde liegende Datenerhebung im ländlichen Raum (siehe Kapitel 2.1) hat zudem gezeigt, dass sich im Untersuchungsgebiet die Anzahl der Zeichen im öffentlichen Raum in den letzten zehn Jahren verdoppelt hat.

Schon seit einigen Jahrzehnten wird in der Soziologie und Humangeographie darüber diskutiert, ob „Stadt“ und „Land“ als Gegensatz und vor allem als wissenschaftlich anwendbare Kategorien überhaupt noch tauglich sind (cf. Cloke 2006; Harding/Blokland 2014: 10-12; Woods 2011: 1-15). „Land“ wurde in diesen Disziplinen lange als funktionales Konzept verwendet, das solche Räume beschrieb, in denen Flächen extensiv zu land- oder forstwirtschaftlichen Zwecken genutzt wurden und die weniger dicht besiedelt waren. Dazu kam die Vorstellung, dass in ländlichen Räumen homogenere Vorstellungen von Identität und Gemeinschaft

\footnotetext{
${ }^{2}$ Siehe in diesem Zusammenhang auch die Kerzen in Fenstern für vermisste oder noch nicht aus der Gefangenschaft zurückgekehrte Soldaten nach dem 2. Weltkrieg sowie die Kerzen in den Fenstern als Ausdruck der Solidarität mit den „Brüdern und Schwestern“ in der DDR nach dem Mauerbau in den 1960er Jahren. Für diesen Hinweis danken wir Ulrich Schmitz/Duisburg-Essen. Die Aktion \#lichtfenster, zu der Bundespräsident FrankWalter Steinmeier am 28. Februar 2021 aufgerufen hat, um ein Zeichen der Solidarität für die Coronaopfer zu setzen, knüpft an diese Praxis an.
} 
dominierten (Cloke 2006: 20). Derartige Konzepte wurden in den 1980er und 1990er Jahren zunehmend als analytische Kategorien in Frage gestellt, denn aus politisch-ökonomischer Perspektive sind Räume ebenso wie soziale Verhältnisse, Beziehungen und Prozesse denselben nationalen und globalen Transformationsprozessen ausgesetzt, was die Unterschiede zwischen urbanen und ländlichen Räumen verringert (cf. Hoggart 1990). Aus sozial-konstruktivistischer Perspektive wird dieser Auffassung allerdings entgegengesetzt, dass zum Teil sehr alte und tief im kollektiven Bewusstsein verankerte Diskurse über „Stadt“ und „Land“ ebenfalls soziale Realitäten schaffen und daher in die wissenschaftliche Betrachtung einbezogen werden müssen. Der theoretische Rahmen, in dem „Land“ im vorliegenden Beitrag konzeptualisiert wird, beruft sich auf Keith Halfacrees Modell zur Definition ländlicher Räume (Halfacree 2006). Es besagt, dass die Vorstellung von ländlichen Räumen zu gleichen Teilen imaginiert, praktiziert und materiell ist, oder anders formuliert, dass die materiellen Gegebenheiten eines Raumes und die Diskurse über ihn die Praktiken bestimmen, mit denen Individuen und Gruppen sowohl Ort als auch Gemeinschaft immer wieder neu konstruieren. Einer der Untersuchungsräume für die vorliegende Untersuchung - die 19 Dörfer der Gemeinde Krummhörn in Ostfriesland - ist demzufolge deshalb ländlich, weil er von Bewohnern, Besuchern und denjenigen, die ihn verwalten und regieren, als „ländlich“ verstanden wird. ${ }^{3}$ Seine materiellen Voraussetzungen prädestinieren ihn für Landwirtschaft, Energiegewinnung und Tourismus, beides führt zu spezifischen sozialen (und damit auch sprachlichen) Praktiken, die mit „Land“ in Verbindung gebracht werden.

Auch die Linguistik hat seit einiger Zeit begonnen, „Stadt“ und „Land“ als soziale Kategorien zu hinterfragen (cf. Auer/Schmidt 2010; Tophinke/Ziegler 2019a). Gleichwohl werden die Kategorien „Stadt“ und „Land“ in vielen Studien nach wie vor verwendet, oftmals auch ohne sie zu definieren oder zu problematisieren. Britain (2017) zeigt, wie auch die sprachwissenschaftlichen Forschungsfelder von den Diskursen zu,,Stadt“ und „Land“ geprägt und bestimmt wurden und werden. Das „Land“ war in den Anfängen der Disziplin der bevorzugte Ort für dialektologische Datenerhebungen zum Zweck der geographischen Kartographierung von Dialektgrenzen. Dabei schrieb die traditionelle Dialektologie dem ländlichen Raum tendenziell diejenigen Sprachformen zu, die von älteren (in der Regel männlichen) und weniger mobilen Informanten gesprochen wurden und damit schon fast nicht mehr existierten (cf. Kamwangamalu/Tovares 2019). Das mit dieser Form der Datenerhebung elizitierte Datenmaterial beschrieb daher lediglich einen (kleinen) Ausschnitt der sprachlichen Realität in den Untersuchungsräumen, da gruppenspezifische Merkmale wie Alter, Geschlecht, soziales Milieu und soziale Mobilität, ethnische Zugehörigkeit und damit verbunden Migration und Sprachkontakt konzeptionell ausgeblendet wurden. Ziel war die Rekonstruktion eines Ortsdialekts, nicht die repräsentative Untersuchung sprachlicher Variation.

Mit Beginn der modernen Soziolinguistik seit den 1960er Jahren wurde die „Stadt“ zur bevorzugten Projektionsfläche für linguistische Untersuchungen. Bis dahin galt die „Stadtsprache“ als „ein das räumliche und soziale Gleichgewicht koexistierender Varietäten störendes Gebilde, das ,verderblichen“ sprachlichen ,Verfall` zu bringen droht“" (Dittmar/Schlieben-Lange 1982:

3 „Rurality is [...] an imagined entity that is brought into being by particular discourses of rurality that are produced, reproduced and contested by academics, the media, policy makers, rural lobby groups and ordinary individuals. The rural is therefore a category of thought.”(Woods 2011: 9). 
9). Ausgangspunkt war die Tatsache, dass die Mehrheit der Sprecherinnen und Sprecher in Städten und nicht auf dem Land lebt und die Feststellung ,[a]ll dialects are both regional and social.“ Denn: „All speakers have a social background as well as a regional location“ (Chambers/Trudgill 1998/2012: 45). Der Fokus auf Städte bedeutete auch einen Fokus auf gegenwartssprachliche Erscheinungen, auf Sprachvariation und auf Fragen der Repräsentativität der Sprecherauswahl, alles Aspekte, die in der traditionellen Dialektologie ausgeblendet wurden. Die neue „urban dialectology“ (Chambers/Trudgill 1998/2012) fand ihren Niederschlag in drei Wellen der Variationsforschung (cf. Eckert 2012). Die Arbeiten in der ersten Welle sind quantitativ ausgerichtet und beschäftigen sich mit dem Zusammenhang zwischen Sprachgebrauch und sozialen Variablen wie Alter, Geschlecht und soziale Schicht. In der zweiten Welle dominieren ethnografische Analysen zur lokalen Bedeutung von Sprachvariation, i. e. Variationsphänomene werden als Kontextualisierungshinweise untersucht. In der dritten Welle wird Variation als Praxis sozialer Positionierung konzeptualisiert und ihre indexikalische Wertigkeit in den Blick genommen. Danach verorten sich Sprecherinnen und Sprecher qua Variation in einer Gesellschaft, wobei die soziale Bedeutung sprachlicher Variablen als grundsätzlich kontextspezifisch und damit veränderlich betrachtet wird. Instruktiv für die vorliegende Untersuchung ist eine Perspektive auf Variation, die die sprachlichen Praktiken (,doing Xese“4) in Hinblick auf ihr Indexikalisierungs- und Positionierungspotenzial (z. B. Positionierung als „Krummhörner“ oder „Ruhri“, siehe Kapitel 4) in den Blick nimmt. Denn, so Eckert (2010: 168): „Residential patterns, local territories, rural and urban spaces, regions and nations all involve the physical placement of distinctive populations and linguistic varieties. And this placement in turn plays a role in reproducing distinctiveness."

Der vorliegende Beitrag untersucht die Reaktionen auf die Corona-Pandemie in den semiotic landscapes in einem ländlichen und einem urbanen Raum. Er orientiert sich dabei an den folgenden Forschungsfragen:

1. Welche Praktiken der Krisenbewältigung zeigen sich in der semiotischen Gestaltung des öffentlichen Raumes?

2. Gibt es Unterschiede zwischen urbanen und dörflichen Praktiken?

3. Welche Rolle spielen regionale Varietäten bei Krisenbewältigungszeichen und welches Indexikalisierungs- und Positionierungspotenzial lässt sich erkennen?

Der Beitrag ist wie folgt strukturiert: Im folgenden Kapitel werden die Untersuchungsräume näher beschrieben (Kapitel 2), danach die Datenerhebung und die Korpora (Kapitel 3). In Kapitel 4 werden die Analysen und Ergebnisse vorgestellt und in Kapitel 5 werden die Ergebnisse kritisch reflektiert und in den Forschungsstand eingeordnet.

\footnotetext{
${ }^{4}$ Cf. in diesem Zusammenhang die Unterscheidung von Johnstone (2013) zwischen „local dialect of Pittsburgh“ und „Pittsburghese“ als kollektiv imaginiertes und mediatisiertes Identitätssymbol.
} 


\section{Untersuchungsräume}

\subsection{Krummhörn (Ostfriesland)}

Die Gemeinde Krummhörn besteht aus 19 Dörfern auf der ostfriesischen Halbinsel mit gegenwärtig rund 12.000 Einwohnern. ${ }^{5}$

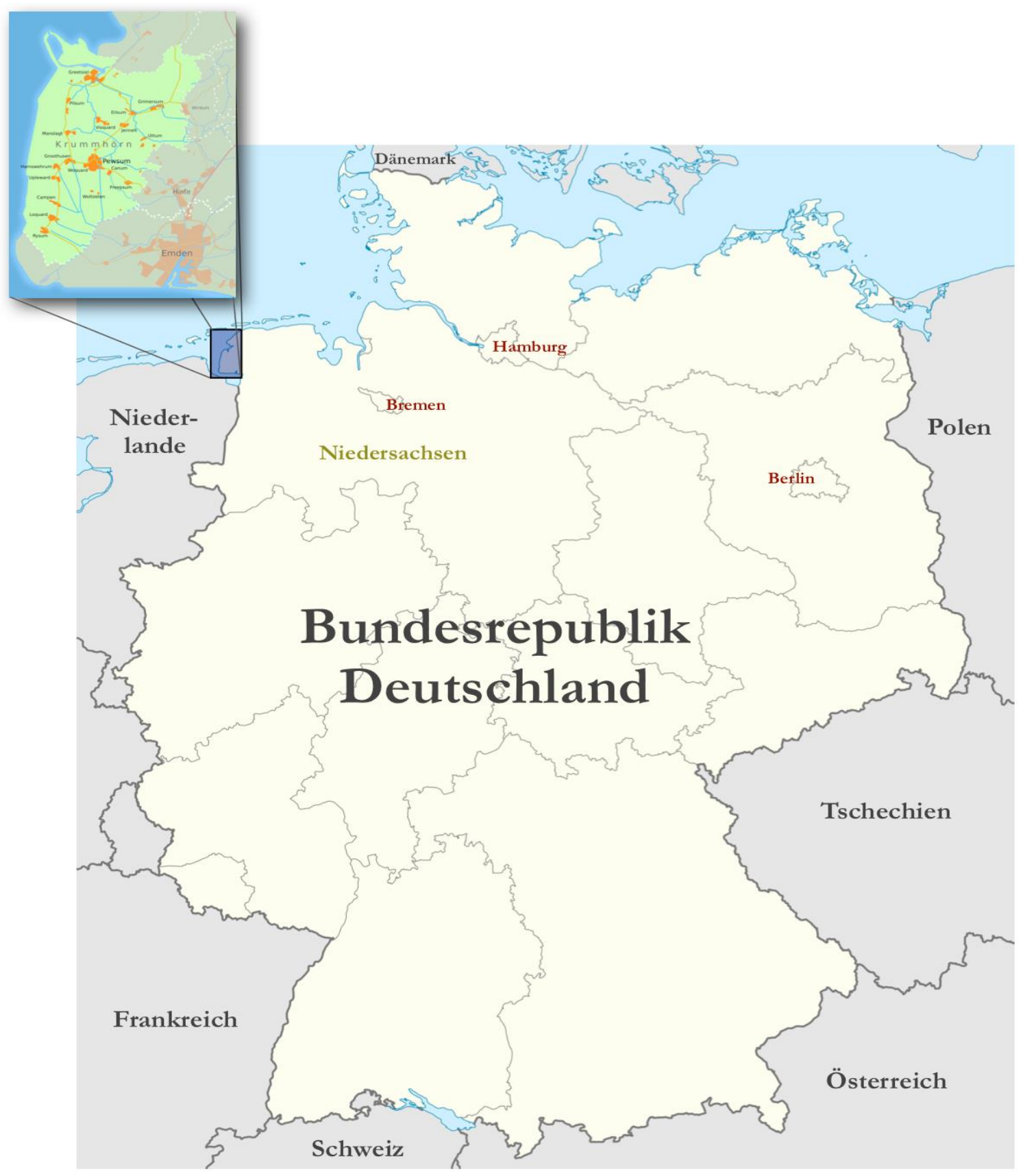

\section{Karte 1: Krummhörn (Kamphues)}

In den vergangenen fünfzig Jahren hat in den Dörfern der Krummhörn ein Strukturwandel stattgefunden, der in vieler Hinsicht mit den Entwicklungen des ländlichen Raumes im globalen

\footnotetext{
${ }^{5}$ Vor zehn Jahren hatte die Gemeinde Krummhörn noch 12.779 Einwohner (cf. Reershemius 2011). Dies bedeutet einen Bevölkerungsrückgang von sechs Prozent, eine typische Entwicklung für viele ländliche Regionen in Europa.
} 
Norden vergleichbar ist (cf. Halfacree 2006; Woods 2011): Während kleinere und mittlere landwirtschaftliche Betriebe mehr und mehr von größeren Unternehmen verdrängt werden (superproductivism), wird die lange Zeit unangefochtene Vorrangstellung landwirtschaftlicher Produktion in der Region zunehmend als wirtschaftlich dominierender Faktor in Frage gestellt. Umweltschutz und Ökologie beginnen seit einiger Zeit eine größere Rolle zu spielen. Tourismus ist ein neuer und wichtiger Teil der Wirtschaft der Region geworden, die sich im Wettbewerb um Besucher positionieren und präsentieren muss. Die 19 Dörfer der Krummhörn waren bis 1972 unabhängige Verwaltungseinheiten, bevor sie zu einer Samtgemeinde zusammengefasst wurden. Gegenwärtig sind die Dörfer in erster Linie Wohnsiedlungen für die benachbarten Kleinstädte, die zu den infrastrukturellen Mittelpunkten geworden sind und wo die Dorfbewohner zur Arbeit oder zur Schule gehen. Ein wichtiger Veränderungsfaktor seit den 1960er Jahren ist eine zunehmende Mobilität: Junge Menschen verlassen die Region, um zu studieren oder um Arbeitsplätze außerhalb des strukturschwachen Ostfrieslands zu finden. Im Jahre 2018 besuchten 128.891 Touristen die Krummhörn, also ungefähr zehnmal so viele Menschen wie die Gemeinde Bewohner hat. Viele Häuser in den historischen Dorfkernen werden von neu Zugezogenen gekauft, die die Region als Touristen kennenlernten und dann beschlossen, nach der Pensionierung ganz dorthin zu ziehen. Migration und Mobilität sind jedoch keine neuen Phänomene: Im 19. Jahrhundert wanderten viele Ostfriesen - nach Schätzungen bis zu $20 \%$ der ostfriesischen Gesamtbevölkerung - aus wirtschaftlichen Gründen aus, vor allem in die USA. In den ersten Jahren nach dem Zweiten Weltkrieg wurde Ostfriesland zum Einwanderungsland für Flüchtlinge und Vertriebene aus den ehemaligen Ostgebieten des vormaligen Deutschen Reiches. Mehrsprachigkeit war historisch ein Merkmal der Region Ostfriesland mit Niederdeutsch als dominanter Vernakularsprache, Deutsch und vormals Niederländisch als Schriftsprachen, Französisch als Sprache der Besatzung und Bildungssprache des 19. Jahrhunderts sowie Resten westjiddischer Varietäten (cf. Reershemius 2007). Obwohl Ostfriesland heutzutage nach wie vor zum Kernland des niederdeutschsprachigen Norddeutschlands gerechnet werden kann, geht auch hier die Verwendung des Niederdeutschen merklich zurück, weil etablierte Kommunikationsdomänen sich verändern oder wegfallen und Kinder nicht mehr mit Niederdeutsch groß werden (cf. Adler et al. 2016). Neben Deutsch als dominanter Standard-, Schrift- und gesprochener Sprache der Gegenwart hat auch die globale Sprache Englisch zunehmend an Bedeutung gewonnen, weil sie normalerweise als erste Fremdsprache an den Schulen unterrichtet wird und vor allem zu Werbezwecken und als Sprache der Jugendkultur eingesetzt wird.

\subsection{Ruhrgebiet}

Das Ruhrgebiet ist eine Metropolregion in Nordrhein-Westfalen mit über fünf Millionen Einwohnern. Anders als andere Metropolregionen (z. B. Greater London) besitzt das Ruhrgebiet kein Zentrum, sondern ist eine polyzentrische Städtelandschaft mit elf kreisfreien Städten, darunter Duisburg, Essen, Bochum und Dortmund. Als eine der wichtigsten Einwanderungsregionen Deutschlands reicht seine Migrationsgeschichte zurück bis in das 19. Jahrhundert. Die Entwicklung des Kohlebergbaus und der Stahl- und Eisenindustrie erhöhte den Bedarf an Arbeitskräften und führte zu mehreren Wellen der Arbeitsmigration, die sich in „Schichten der Vielfalt" (Ziegler et al. 2018: 22) zeigen. Die erste Welle der Arbeitsmigration, von 1871 bis 1914, brachte Migranten vor allem aus dem Osten des Deutschen Reiches und aus Polen. In der 
zweiten Arbeitsmigrationswelle, die Ende der fünfziger Jahre begann und 1973 mit dem sog. Anwerbestopp endete, kamen die Migranten, damals noch „Gastarbeiter“ genannt, überwiegend aus südeuropäischen Ländern wie Italien, Griechenland, Türkei, Jugoslawien, Spanien und Portugal. Eine dritte Migrationswelle begann Ende der 1980er Jahre mit der Ankunft von Aussiedlern aus Osteuropa, i. e. aus Polen und der ehemaligen UdSSR, und einer wachsenden Zahl von Asylbewerbern. In den letzten zehn Jahren verzeichnete das Ruhrgebiet eine Zunahme der armutsbedingten Migration aus Bulgarien und Rumänien sowie einen großen Zustrom von Flüchtlingen aus Syrien. Insgesamt haben diese Migrationswellen zu Städten und Stadtvierteln mit hoher ethnisch-kultureller Diversität und besonderen Siedlungsmustern geführt. Diese Siedlungsmuster basieren auf einem ,degree of unequal distribution of the resident population over the territory of a city in terms of social status characteristics (social status of residential areas), of family forms and life styles (family status), and in terms of the ratio of Germans to immigrants" (Strohmeier/Bader 2004). Ein wesentliches Merkmal des Ruhrgebiets ist das Nord-Süd-Gefälle entlang der Autobahn A 40, die auch als „Sozialäquator“ (Kersting et al. 2009) bezeichnet wird. Die A 40 teilt die Städte Duisburg, Essen, Bochum und Dortmund in nördliche Stadtteile mit einer ethnisch diverseren, ärmeren und weniger gebildeten Bevölkerung und in südliche Stadtteile mit einer ethnisch weniger diversen, wohlhabenderen und gebildeteren Bevölkerung (cf. Kersting et al. 2009).

Im Zuge der Industrialisierung und Modernisierung wurden im 19. und beginnenden 20. Jahrhundert die Dialekte zugunsten einer regional geprägten Alltagssprache abgebaut. Das Ruhrdeutsche weist zwar noch Reliktformen des niederfränkischen und westfälischen Substrats auf, teilt aber gleichzeitig viele Merkmale mit der allgemeinen Umgangssprache, von der es deshalb auch nicht so einfach abzugrenzen ist. Mit den verschiedenen Einwanderungswellen nahm auch der Anteil der anderen Sprachen als Deutsch zu, die im Ruhrgebiet verwendet werden. Neben den Migranten- bzw. Herkunftssprachen Arabisch, Bulgarisch, Italienisch, Polnisch, Russisch und Türkisch (um die Sprachen der größten Sprechergruppen zu nennen) sind auch die Nachbarsprachen Niederländisch und Französisch wegen der Pendler und Touristen und das Englische als internationale Sprache von Bedeutung (cf. Ziegler et al. 2018: 56-61 und 170-171).

Stellvertretend für das Ruhrgebiet wurde für diese Untersuchung die Stadt Essen gewählt. Essen hat 591.018 Einwohner (cf. Essen.de) und weist - ebenso wie die Städte Duisburg, Bochum und Dortmund - eine sozialräumliche Segregation nördlich und südlich der A 40 auf.

\section{Datenerhebung und Korpora}

Im Rahmen einer Langzeitstudie zu den semiotic landscapes der Krummhörn (Reershemius 2011, 2020, 2021) wurden zwischen April und Juni 2020 in den 19 Dörfern alle sprachlichen und bildlichen Zeichen außer Verkehrsschildern im öffentlichen Raum fotografiert und inventarisiert. Das so entstandene Krummhörn-Korpus $2020^{6}$ umfasst 2628 Zeichen. Davon nehmen 204 Zeichen, also knapp acht Prozent, direkten oder indirekten Bezug auf die CoronavirusPandemie (Krummhörn-Pandemie-Korpus $\mathrm{KPK}^{7}$ ). Die inventarisierten Zeichen des KPK zeichnen sich durch Besonderheiten im Hinblick auf ihre Materialität und die Positionierung

\footnotetext{
${ }^{6}$ Es handelt sich bei diesem Korpus um kein frei zugängliches Korpus.

${ }^{7}$ Es handelt sich bei diesem Korpus um kein frei zugängliches Korpus.
} 
der Zeichen (Emplacement) aus: Viele der zwischen April und Juni 2020 im Untersuchungsraum inventarisierten sprachlichen und bildlichen Zeichen wurden schnell und mit einfachen Mitteln produziert (siehe Abbildung 1):

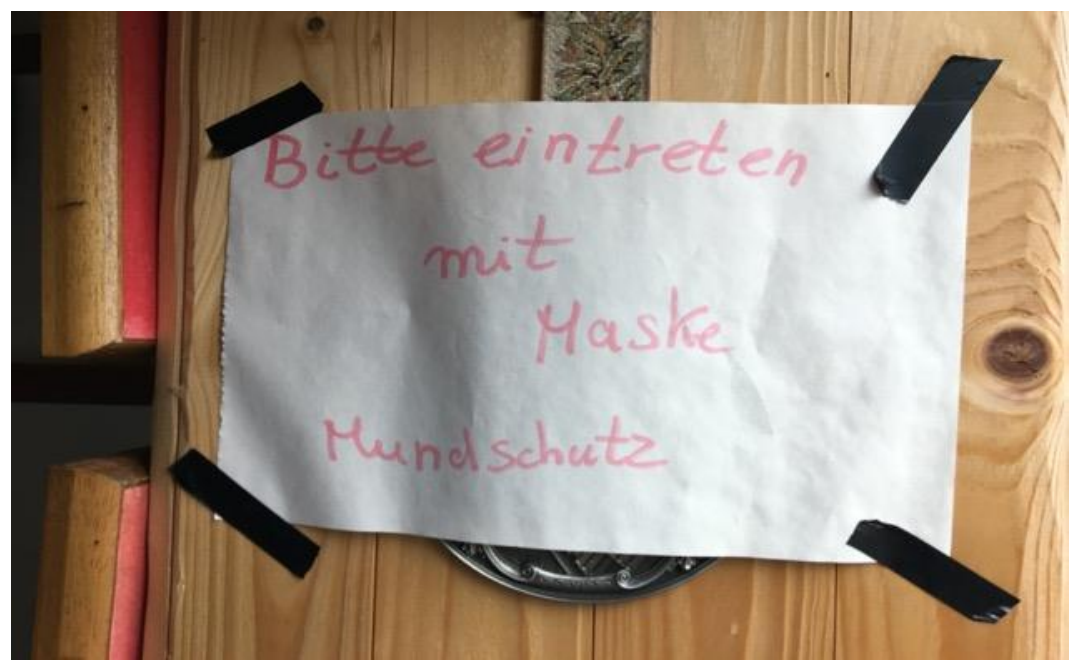

Abbildung 1: Ad hoc produzierte Zeichen (KPK 30.05.2020)

Die Materialität von regulativen Zeichen wie in Abbildung 1 bedeutet, dass sie zwar schnell produzierbar sind, aber Umwelteinflüssen nicht lange standhalten können. Auch wenn es in einem Untersuchungsraum wie Krummhörn sprachliche Zeichen gibt, die Jahrhunderte alt sind, so ist die Gestaltung des öffentlichen Raumes mit bildlichen und sprachlichen Mitteln kontinuierlich einem Prozess der Fluktuation und der Veränderung unterworfen. Ein Zeicheninventar eines öffentlichen Raumes zu einem gegebenen Zeitpunkt ist daher immer eine Momentaufnahme. Die Zeichen, die im Zusammenhang mit der Coronavirus-Pandemie im öffentlichen Raum erschienen sind, sind mehr noch als andere derartigen Veränderungsprozessen ausgesetzt.

Die Zeichen des KPK sind zudem auf spezifische Weise im Raum positioniert (Emplacement): Die meisten Corona-Zeichen finden sich an Fenstern und Türen von Privathäusern oder Geschäften, dazu kommen die in jedem einzelnen Dorf vorhandenen Schaukästen der Gemeindeverwaltung und der Kirche, manchmal noch der Dorffeuerwehr, des Sportvereins oder des Dorfgemeinschaftsvereins.

Die Daten für das Ruhrgebiet wurden in der Zeit von März bis Juli 2020 gesammelt, einige wenige Daten wurden auch noch im Herbst 2020 erhoben, um illustrieren zu können, inwieweit sich die Dynamik der Pandemie und die damit verbundenen Maßnahmen (Lockdown im Frühjahr, Lockerung der Maßnahmen im Sommer und zweiter Lockdown im Herbst/Winter 2020) in der Semiotik des öffentlichen Raums abbilden. Gesammelt wurden die Daten in der Stadt Essen, und zwar in Anlehnung an das Metropolenzeichen-Projekt (cf. Ziegler et al. 2018) nördlich und südlich der A 40: Nördlich der A 40 wurden die Daten in der Innenstadt und dem Stadtteil Essen-Altenessen, südlich der A 40 in den Stadtteilen Werden und Kettwig erhoben. Die Daten für die Stadt Essen, die sich auf die Coronavirus-Pandemie beziehen, umfassen insgesamt 271 Fotodaten.

Für beide Teilkorpora wurde nach der Regel „ein Zeichen - ein Foto“ verfahren, i. e. Aushänge, Plakate und Aufkleber, die mehrmals an ein und demselben Geschäft angebracht sind, wurden 
nicht mehrfach aufgenommen (eine Vorgehensweise, die auch dem Metropolenzeichen-Projekt zugrunde liegt). Für das Metropolenzeichen-Projekt wurden die vier großen Ruhrgebietsstädte Duisburg, Essen, Bochum und Dortmund gewählt und für jede Stadt ein Stadtteil nördlich und südlich der A 40 sowie zentrale infrastrukturelle Einheiten (Hauptbahnhof, Bürgerbüro, Kultureinrichtung, Kita) untersucht. Die Datenbasis für das Metropolenzeichen-Korpus ${ }^{8}$ umfasst insgesamt 25.504 Fotodaten, wobei die Datenmenge für die einzelnen Stadtteile zwischen 1236 und 6057 (cf. Ziegler/Schmitz im Druck) schwankt - trotz vergleichbarer Größe der Untersuchungsgebiete. Gemessen an den 8158 Fotodaten für die Stadtteile der Stadt Essen beläuft sich der Anteil der Daten des Essen-Pandemie-Korpus ${ }^{9}$ (EPK) mit direktem und indirektem Bezug zur Pandemie auf 3,3 \% und ist somit deutlich kleiner als der Anteil des Krummhörn-PandemieKorpus mit knapp $8 \%$ bezogen auf das Krummhörn-Korpus. Dieser Unterschied ist bemerkenswert. Er erklärt sich vor allem damit, dass im Metropolenzeichen-Korpus wesentlich mehr transgressive Zeichen (Sticker, Tags, Graffitis) enthalten sind als im Krummhörn-Korpus. Städte sind die Hochburgen (und waren auch die Ursprungsorte) für subkulturelle Praktiken wie Taggen und das Herstellen von Graffitis. Graffitis, Tags und Sticker gehören zum Stadtbild, sie gelten als integraler Bestandteil des urbanen Raums (cf. Tophinke 2016). Dies erklärt den hohen Anteil von transgressiven Daten für die Stadt Essen, der mit 3306 Bilddaten mehr als ein Drittel der Gesamtdaten ausmacht.

\section{$4 \quad$ Analyse}

\subsection{Regulativ-informierende Zeichen im KPK und im EPK}

Nach Androutsopoulos (2020: 294-296) bestehen die zentralen Funktionen von Zeichen im öffentlichen Raum, die sich auf die Coronavirus-Pandemie beziehen, aus a) Regulation, b) Information und c) Affekt. Um auch die Daten erfassen zu können, die kritische Positionierungen gegenüber den Maßnahmen und Regelungen zur Bekämpfung der Coronavirus-Pandemie enthalten, wurde die Zusatzkategorie d) Kritik eingeführt. Die 204 Zeichen des Krummhörn-Pandemie-Korpus verteilen sich auf diese Funktionen wie folgt (siehe Tabelle 1), wobei jeweils die dominante Funktion für die Zeichen bestimmt wurde:

\begin{tabular}{|l|r|r|}
\hline Krummhörn-Pandemie-Korpus & & \\
\hline Regulation & 104 & $51 \%$ \\
\hline Information & 44 & $22 \%$ \\
\hline Affekt & 56 & $27 \%$ \\
\hline Kritik & 0 & $0 \%$ \\
\hline Gesamt & $\mathbf{2 0 4}$ & \\
\hline
\end{tabular}

Tabelle 1: Funktionale Verteilung der Zeichen im KPK

Die Zeichen des EPK umfassen insgesamt 271 Fotodaten. Diese Daten verteilen sich wie folgt auf die Kategorien a) Regulation, b) Information, c) Affekt und d) Kritik, siehe Tabelle 2:

\footnotetext{
${ }^{8}$ Es handelt sich bei diesem Korpus um kein frei zugängliches Korpus.

${ }^{9}$ Es handelt sich bei diesem Korpus um kein frei zugängliches Korpus.
} 


\begin{tabular}{|l|r|r|}
\hline Essen-Pandemie-Korpus & & \\
\hline Regulation & 121 & $45 \%$ \\
\hline Information & 102 & $37 \%$ \\
\hline Affekt & 43 & $16 \%$ \\
\hline Kritik & 5 & $2 \%$ \\
\hline Gesamt & $\mathbf{2 7 1}$ & \\
\hline
\end{tabular}

Tabelle 2: Funktionale Verteilung der Zeichen im EPK

Der Vergleich der Korpusdaten für die Krummhörn und die Stadt Essen zeigt, dass in beiden Korpora die regulatorischen Zeichen überwiegen, im KPK allerdings mit deutlicherem Abstand vor den informativen Zeichen. Bemerkenswert ist der Anteil der affektiven Zeichen in beiden Korpora sowie die Tatsache, dass kritische Bezugnahmen zur Corona-Pandemie nur im EPK vorkommen. ${ }^{10}$

Die Zuordnung der Zeichen zu den Kategorien Regulation, Information und Affekt ist nicht immer eindeutig und erfordert einen interpretativen Akt als Teil der quantitativen Analyse. Information und Regulation sind in vielen Fällen miteinander verbunden (siehe Abbildungen 2 und 3):

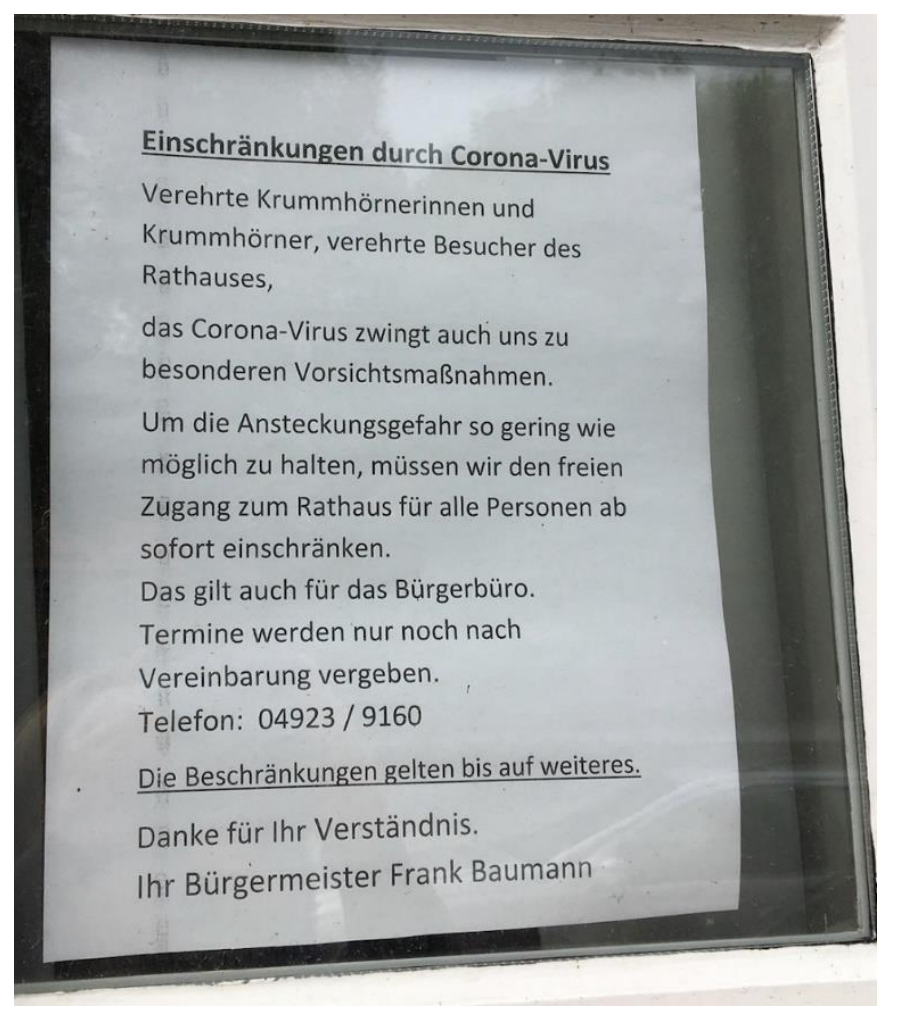

Abbildung 2: Anschreiben des Bürgermeisters (KPK 14.05.2020)

\footnotetext{
10 Das Fehlen Corona-kritischer Zeichen im KPK ist bemerkenswert. Eine mögliche Erklärung wäre hier, dass die Krisenkommunikation der Gemeinde Krummhörn von Beginn der Pandemie an vergleichsweise erfolgreich war. Der Bürgermeister hatte sich sowohl im öffentlichen Raum als auch online direkt an die Bewohner der Krummhörn gewendet und alle Maßnahmen - auf Deutsch und auf Niederdeutsch - dargestellt und erläutert.
} 
In diesem Schreiben des Krummhörner Bürgermeisters werden die Bewohner der Gemeinde über aktuelle Schließungen informiert, wobei die informierenden Texte zugleich ein bestimmtes Verhalten einfordern, also regulativ sind. Diese Überlagerung und Mischung der Funktionen finden sich auch im EPK. Dabei zeigen die Daten nicht nur, dass die regulatorischen Zeichen häufig informierende Textpassagen enthalten, um z. B. Maßnahmen zu erläutern, zu autorisieren und zu legitimieren ${ }^{11}$, sondern auch, dass die Gebote und Verbote häufig mit der Textsortenbezeichnung „Information“ oder „Hinweis“ versehen werden, um die Aufmerksamkeit der Kunden, Gäste, Patienten etc. zu gewinnen und die Ge- und Verbote höflich zu rahmen, siehe Abbildung 3:

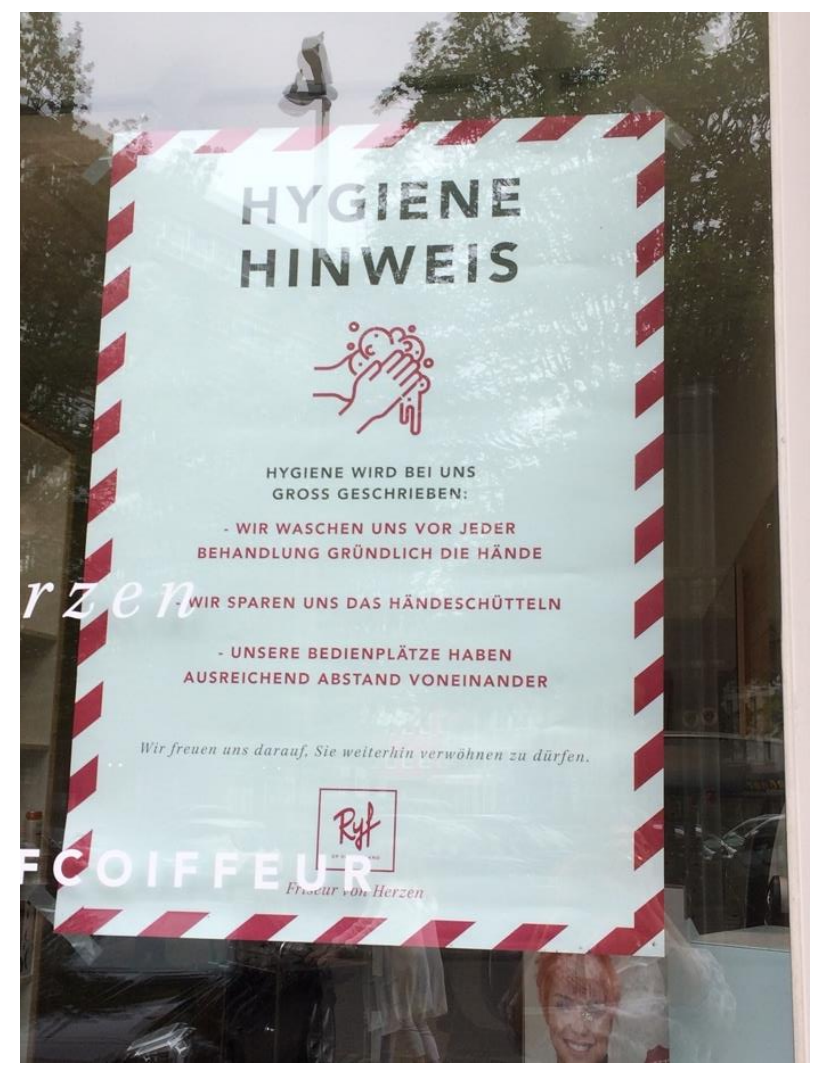

Abbildung 3: Hygiene-Hinweis (EPK, Bildnummer 1449 - 17.07.2020)

Zur Mischung bzw. Kombination von Funktionen kommt es in beiden Korpora auch häufig dort, wo die Information oder Verhaltensregulation mit dem Appell „Bleiben Sie gesund“ verbunden werden (siehe Abbildung 4). So heißt es etwa auf einem Aushang eines Beerdigungsinstitutes in fast schon geschäftsschädigender Absicht: „Wir möchten, dass Sie gesund bleiben“, siehe Abbildung 5:

\footnotetext{
11 Mit dem Verweis auf Gesetze, Beschlüsse und Verordnungen des Landes und der Kommune (siehe Zusätze wie „Verordnungen des Ordnungsamtes“, „Laut dem Gesundheitsamt Essen“ und „Corona-Regeln der Regierung“) erhalten die Aushänge und Schilder ihre normative Kraft.
} 

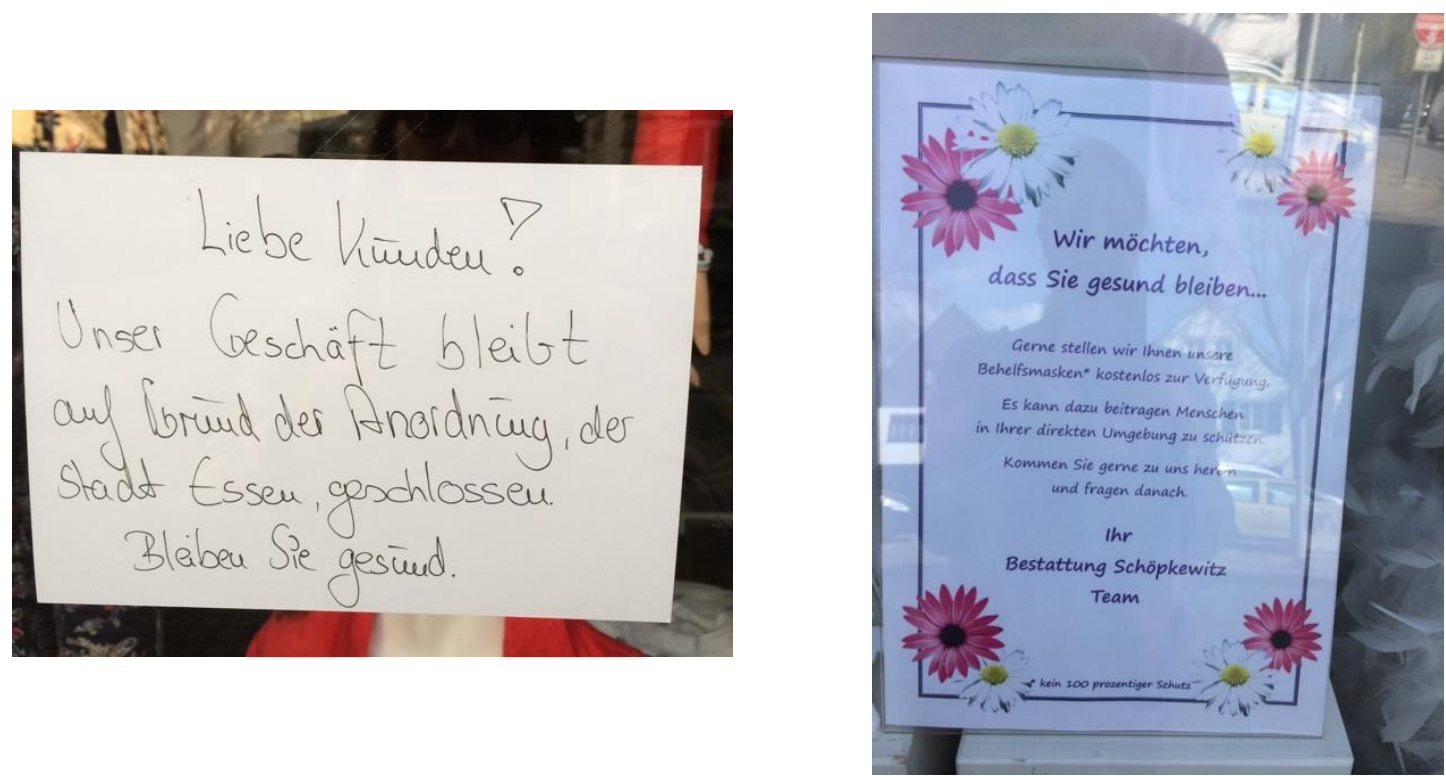

Abbildungen 4 und 5: Kombination der Informations- und Appellfunktion (EPK, Bildnummmer 0576 - 25.03.2020 und 0667 - 07.04.2020)

Darüber hinaus finden sich Beispiele von komplexen Zeichen, die alle drei Funktionen miteinander verbinden, wenn etwa in einem Schaukasten einer Dorfgemeinschaft über die Notbetreuung im Kindergarten informiert, die aktuellen Beschränkungsregeln erwähnt und noch ein aufmunterndes Bild zu diesem Arrangement hinzugefügt wird (siehe Abbildung 6):

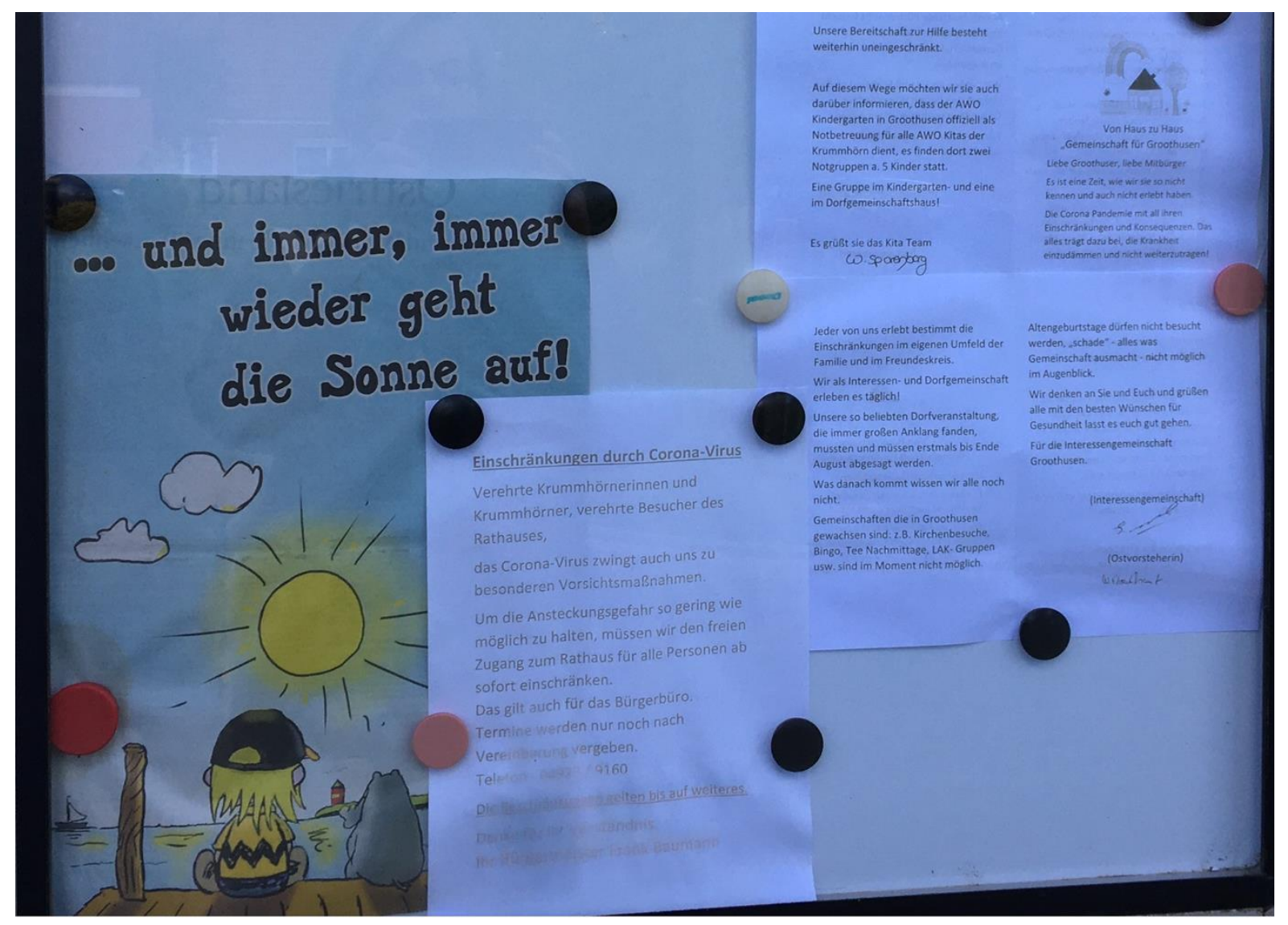

Abbildung 6: Informationsschaukasten einer Dorfgemeinschaft e. V. (KPK 04.05.2020) 
Regulativ-informierende Zeichen erschienen in den Dörfern der Krummhörn und in der Stadt Essen in zwei Phasen, zunächst während des Lockdowns (von Mitte März bis Mitte Mai 2020) und nachdem die Maßnahmen zunehmend gelockert wurden (ab Mitte Mai). In der ersten Phase ging es vor allem darum, die neuen Regeln für veränderte soziale Praktiken bekannt zu machen. Diese Zeichen erschienen an Geschäften und infrastrukturellen Einrichtungen sowie in den Schaukästen verschiedener Institutionen in der Krummhörn und in der Stadt Essen; es ging dabei in erster Linie um Schließungen (siehe Abbildung 2).

Ab Mitte Mai wurde an denselben Lokalitäten ausgeführt, wann und unter welchen Bedingungen die Schließungen aufgehoben werden und welche Regeln beachtet werden müssen, wie zum Beispiel das Tragen von Gesichtsschutz und das Einhalten eines gewissen Abstands (siehe Abbildungen 7 und 8).

\section{Klopfen Sie gerne an, wir sind für Sie da!}

Wenn Sie Erkältungssymptome zeigen oder sich unwohl fühlen, sehen Sie bitte von einem persönlichen Besuch ab. In diesem Fall rufen Sie uns bitte an oder schreiben uns eine E-Mail. Herzlichen Dank! Ihr Versicherungsbüro Ralf Ludwig Abbildung 7: Regulatives Zeichen an einem Versicherungsbüro (KPK 14.05.2020) 


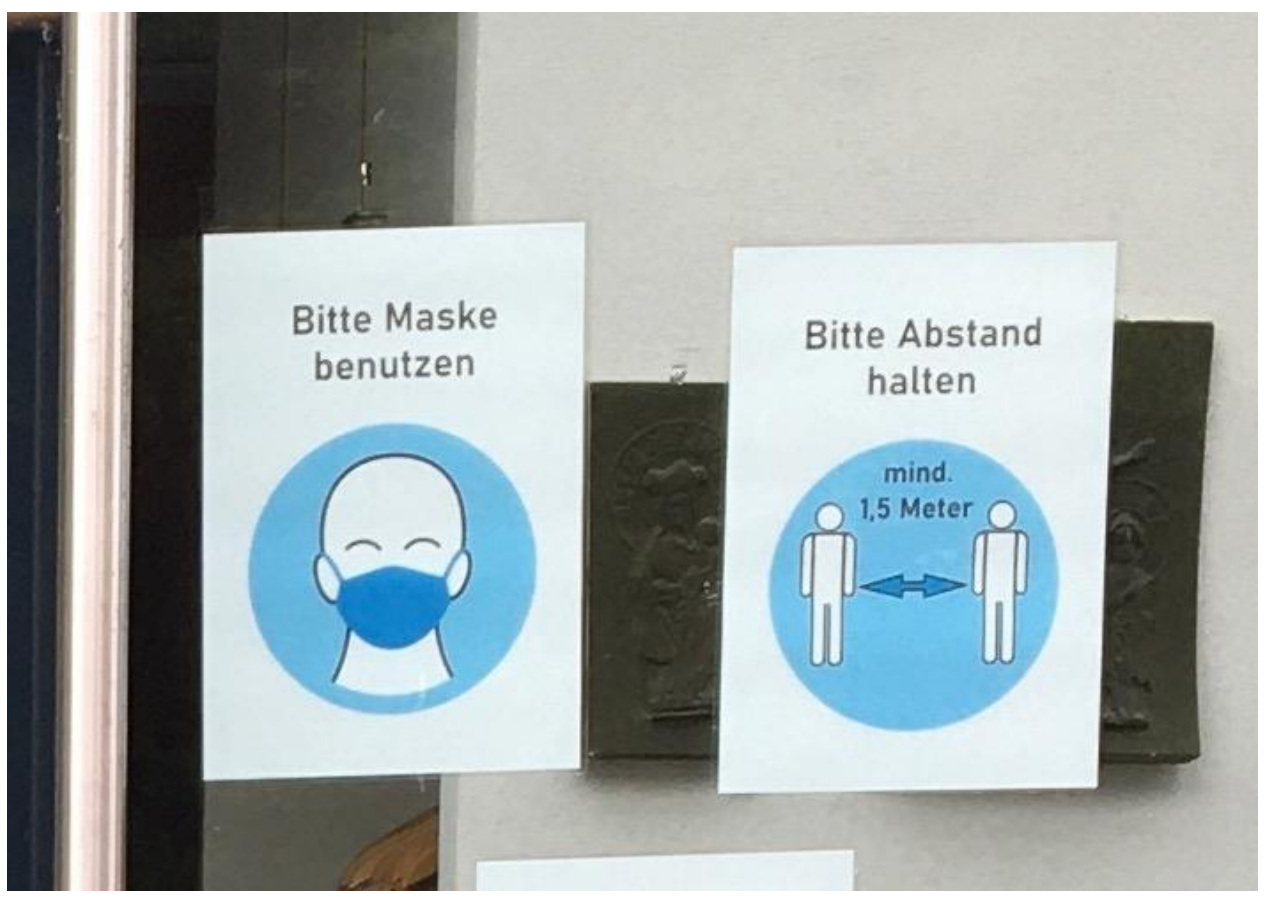

Abbildung 8: Regulative Zeichen an der Tür eines Gemeindehauses (KPK 16.05.2020)

Abbildung 8 zeigt, dass man in der zweiten Phase bereits normierte und vorgedruckte Zeichen zur Verfügung hatte, die das Tragen von Masken und die Einhaltung der Abstandsregeln auf einen Blick und mit Hilfe von bildlichen Mitteln illustrierten. Bei den Zeichen der ersten Phase lässt sich ein klarer Fokus auf Text beobachten, in dem identifizierbare Einzelpersonen - Geschäftsinhaber, Bürgermeister, Pastoren etc. - sich direkt an die Bevölkerung wendeten (,Verehrte Krummhörnerinnen und Krummhörner"), um die neuen Bedingungen zu erklären und für Verständnis zu werben. Für beide Phasen der regulativ-informierenden Zeichen gilt, dass sie eingesetzt wurden, um die von außen und gesetzlich geänderten sozialen Praktiken zu vermitteln.

Insgesamt lässt sich feststellen, dass die für Texte im öffentlichen Raum so typische sprachliche, inhaltliche und kognitive Kürze (cf. Ziegler et al. 2018: 132 und Klug/Pappert 2020) für Zeichen mit Bezug zur Coronavirus-Pandemie (insbesondere in den Anfangszeiten der Pandemie) nicht zutrifft. So dominieren sowohl in der Krummhörn als auch in Essen zu Beginn der Pandemie textlastige und sprachlich komplexe Aushänge und Plakate, die erst mit dem Voranschreiten der Pandemie nach und nach durch übersichtlichere und einfacher zu erfassende TextBild-Kombinationen oder auch formularartige Aushänge ersetzt werden, die eine gewisse Usualität der Textsorten und dementsprechendes Textsorten- und Alltagswissen voraussetzen. Die Hinweise, Ge- und Verbote, in der ersten Phase der Pandemie noch ergänzt durch Erläuterungen, Begründungen, Legitimierungen und Autorisierungen, kommen im weiteren Verlauf der Pandemie immer häufiger ohne diese Bestandteile aus. Gleichzeitig nimmt die syntaktische Komplexität ab, minimalistische Konstruktionen wie Konstruktionen mit deontischen Infinitiven $^{12}$ („Bitte nicht hinsetzen. Only for takeaway“, Bildnummer 0848 EPK) und verblose

\footnotetext{
12 Deontische Infinitive „denotieren Handlungen, mit denen ein menschlicher Akteur eine intentionale Aktivität ausführt oder durch eine solche eine Zustandsveränderung bewirkt" und „kategorisieren sie als geboten, verboten, erlaubt oder normativ indifferent.“ (Deppermann 2006: 241, 243).
} 
Konstruktionen („Rechts nur Ausgang“, Bildnummer 0611 EPK) nehmen dagegen zu - typische Kennzeichen ortsfester Schriftlichkeit. Damit zeigt sich hier im Zeitraffer eine Entwicklung, wie sie von Gilles/Ziegler (2019) für die Entwicklung der Textsorte „Bekanntmachung“ für den Zeitraum vom 18. bis zum 20. Jahrhundert beschrieben wird.

\subsection{Affektive Zeichen im KPK und EPK}

Während regulativ-informierende Zeichen in einer Krisensituation wie der Pandemie zu erwarten gewesen sind, ist die Menge und Gestaltung der affektiven Zeichen bemerkenswert und wird deshalb im Folgenden näher beleuchtet. Die Mehrheit dieser Zeichen konnte im Kontext von Privathäusern beobachtet werden. Frühere Untersuchungen zur semiotischen Gestaltung des öffentlichen Raumes in Krummhörn haben bereits gezeigt, dass das Privathaus bei der Konstruktion von bedeutungsvollen Orten mithilfe von semiotischen Mitteln auf dem Land eine besondere Rolle zu spielen scheint (cf. Reershemius 2011, 2020, 2021). Während der Pandemie und besonders während der ersten Phase des Lockdowns mussten die Menschen gezwungenermaßen mehr Zeit zu Hause verbringen und haben ihre Wohnräume bzw. ihren Garten zum Ausstellungsraum umfunktioniert. Die so präsentierten Zeichen lassen sich globalen, regionalen und lokalen Diskursen zuordnen.

Global: Während der Pandemie konnte sich der Regenbogen als Symbol für Hoffnung in weiten Teilen der Welt durchsetzen. Entsprechend lassen sich in beiden Korpora zahlreiche Regenbogenbilder beobachten (siehe Abbildungen 9 und 10):

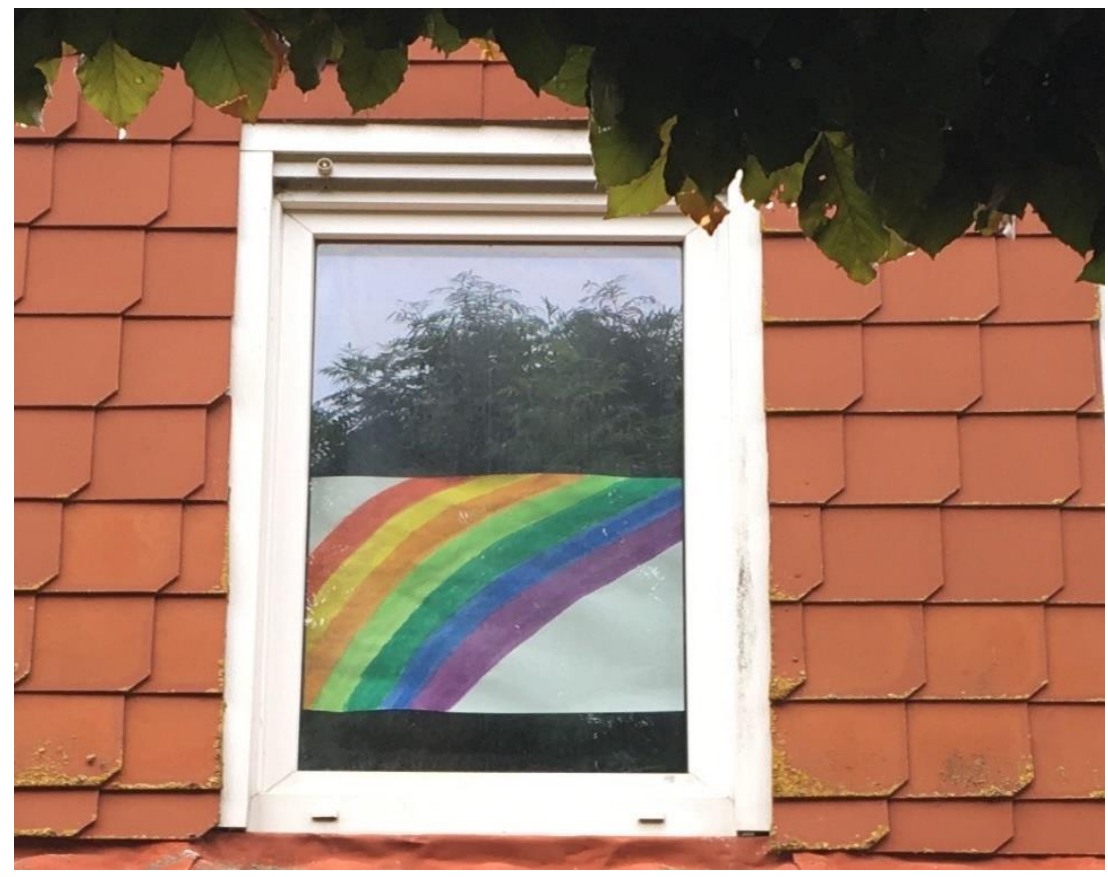

Abbildung 9: Regenbogen in Ostfriesland (KPK 30.05.2020) 


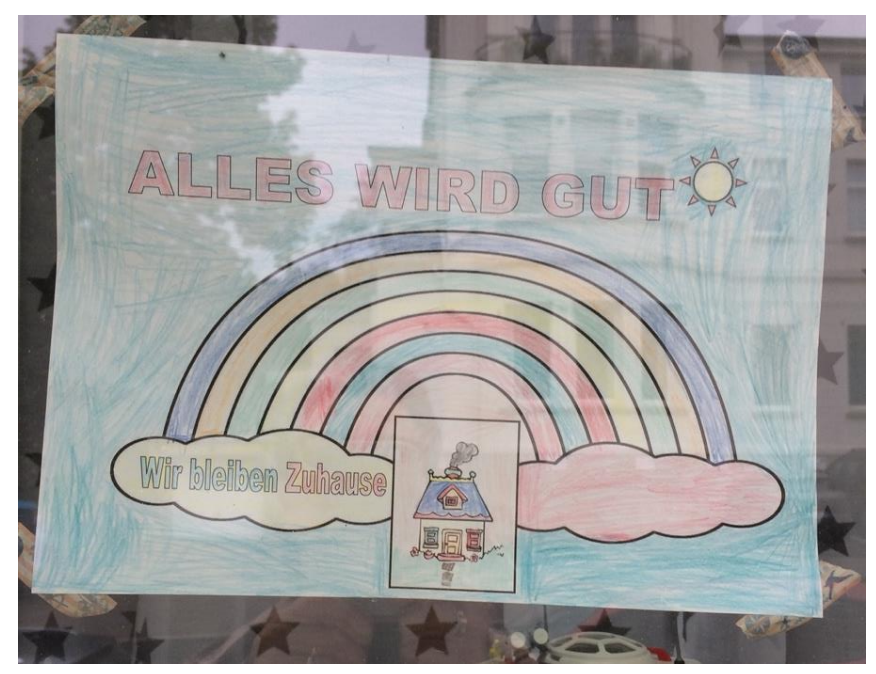

Abbildung 10: Regenbogen an einem Fenster in Essen (EPK, Bildnummer 1309 - 16.07.2020)

Die meisten Regenbogenzeichen sind handgemalt und wurden in Fenstern, an Türen oder Gartenzäunen angebracht. Einige Regenbogenzeichnungen waren vorgedruckt, viele zeigen die Slogans „Wir bleiben zuhause“ oder „Alles wird gut“. Regenbögen fanden sich im KPK auch als Kreidezeichnungen an Hauswänden und als bunt gemalte Steine im Bereich des Hauseingangs (Abbildung 11).

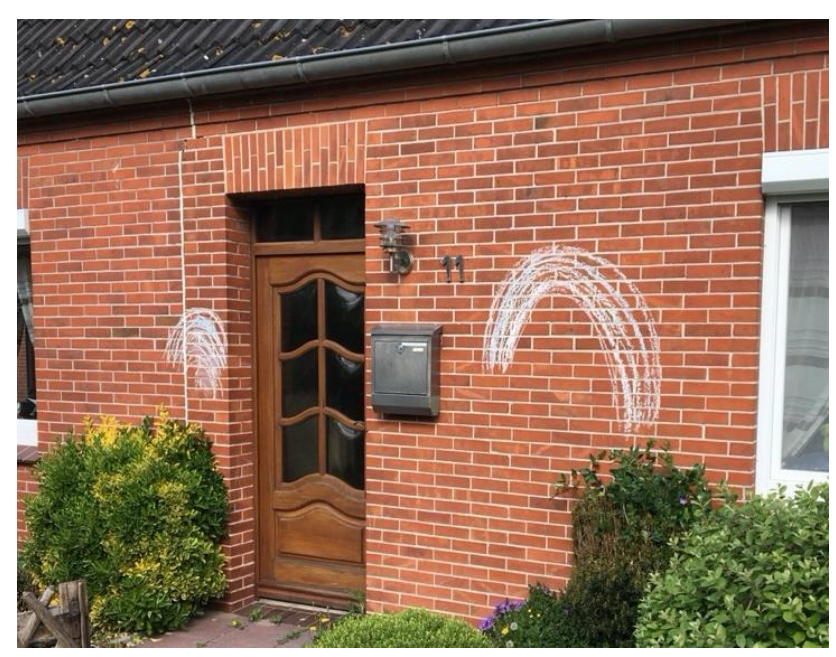

Abbildung 11: Regenbögen als Kreidezeichnung (KPK 23.04.2020)

Eine Variation des Regenbogenmotivs stellt das Motiv der Sonne dar. Während das Regenbogenmotiv im EPK sich nicht nur in Fenstern von Privathäusern und damit im Übergangsbereich von öffentlichem Raum und privatem Wohnraum findet, sondern auch vereinzelt an Fassaden kultureller Einrichtungen wie dem Grillo-Theater in Essen, kommt das Sonnenmotiv fast ausschließlich im öffentlichen Raum im Kontext von Geschäften und dergleichen vor. Zusammen mit der aufmunternden Aufforderung: „Bleiben Sie gesund“ findet es sich z. B. als Kreidezeichnung auf dem Gehweg vor dem Eingang einer Apotheke in Essen-Kettwig (siehe Abbildung 12): 


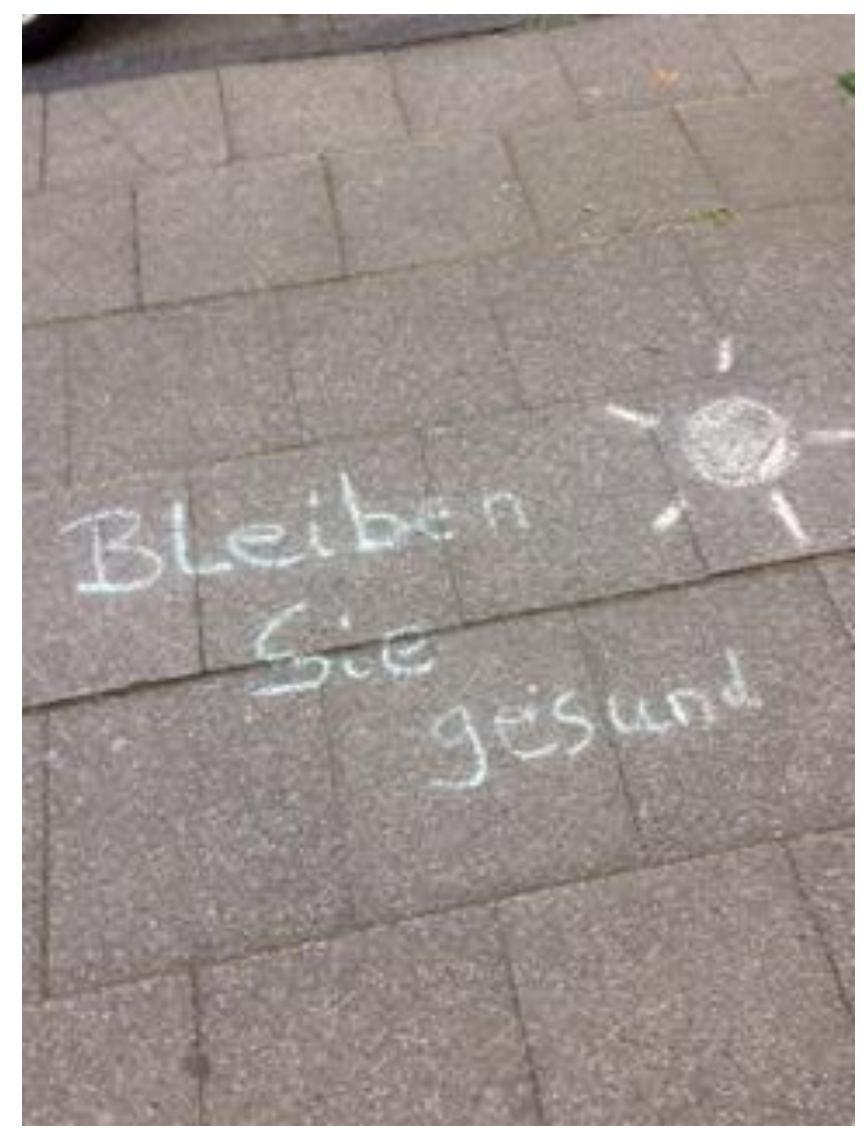

Abbildung 12: Sonne als Kreidezeichnung in Essen (EPK, Bildnummer 0923 - 23.04.2020)

Regional: Unter den emotiven Zeichen des KPK fallen zwei immer wiederkehrende Text-BildKombinationen auf, die ursprünglich in den Lokalzeitungen publiziert und dann von den Leserinnen und Lesern kopiert wurden. Es handelt sich dabei um Cartoons, die von dem aus Ostfriesland stammenden Entertainer Otto Waalkes verfasst wurden. Die Kopien wurden in den Fenstern von Privathäusern, Geschäften, aber auch in Schaukästen und an anderen öffentlichen Orten der Krummhörn Dörfer angebracht (siehe Abbildungen 13):

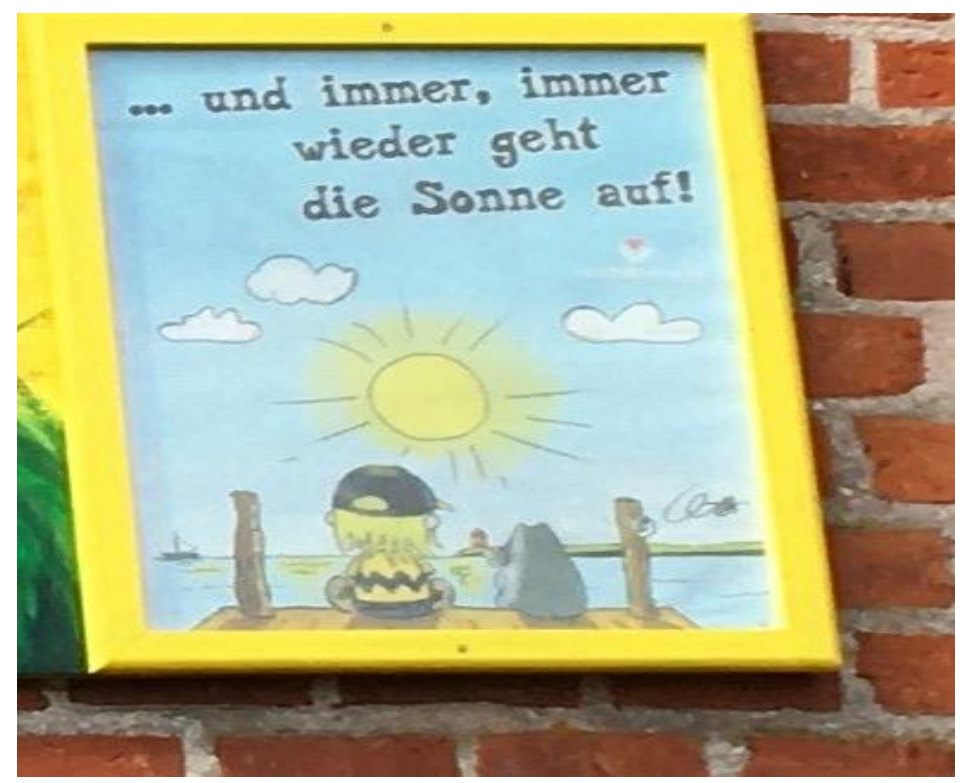

Abbildung 13: Otto - und immer, immer wieder geht die Sonne auf (KPK 23.05.2020) 
Die Zeichnung zeigt eine Figur, die Otto mit der von ihm erfundenen Fantasiefigur des Ottifanten zeigt, wie sie einen Sonnenaufgang am Meer beobachten. Die Zeichnung ist weiterhin lokalisiert, weil sie den Leuchtturm von Pilsum in der Krummhörn zeigt, einem Schauplatz aus einem der Kinofilme von Otto Waalkes. Als Slogan wurde eine Zeile aus einem populären Schlager aus den 1970er Jahren gewählt: „und immer, immer wieder geht die Sonne auf“, ein hoffnungsvoller Allgemeinplatz mit großem Wiedererkennungswert, vor allem bei den älteren Generationen.

Der zweite im Rahmen des KPK oft kopierte und ausgestellte Cartoon von Otto Waalkes zeigt den Ottifanten in einem Lehnstuhl mit einer Tasse Tee, dem ostfriesischen Nationalgetränk, zusammen mit dem Text ,Schön zu Hause bleiben und ne leckere Tasse Tee TRINKEN. Das is GESUND. Dann geht die schlechte Zeit auch schneller vorbei“. Dieses Arrangement appelliert vermutlich auch eher an die älteren Generationen und an Bewältigungsstrategien wie dem Fokus auf die kleinen Freuden des Alltags, hier im regionalen Gewand des Teetrinkens. Wie man in Abbildung 14 sehen kann, wurden diese Zeichen auch an Türen und Fenstern von gewerblichen Betrieben angebracht, was auf eine gewisse Privatisierung des Professionellen in der Zeit der Krise hindeutet.

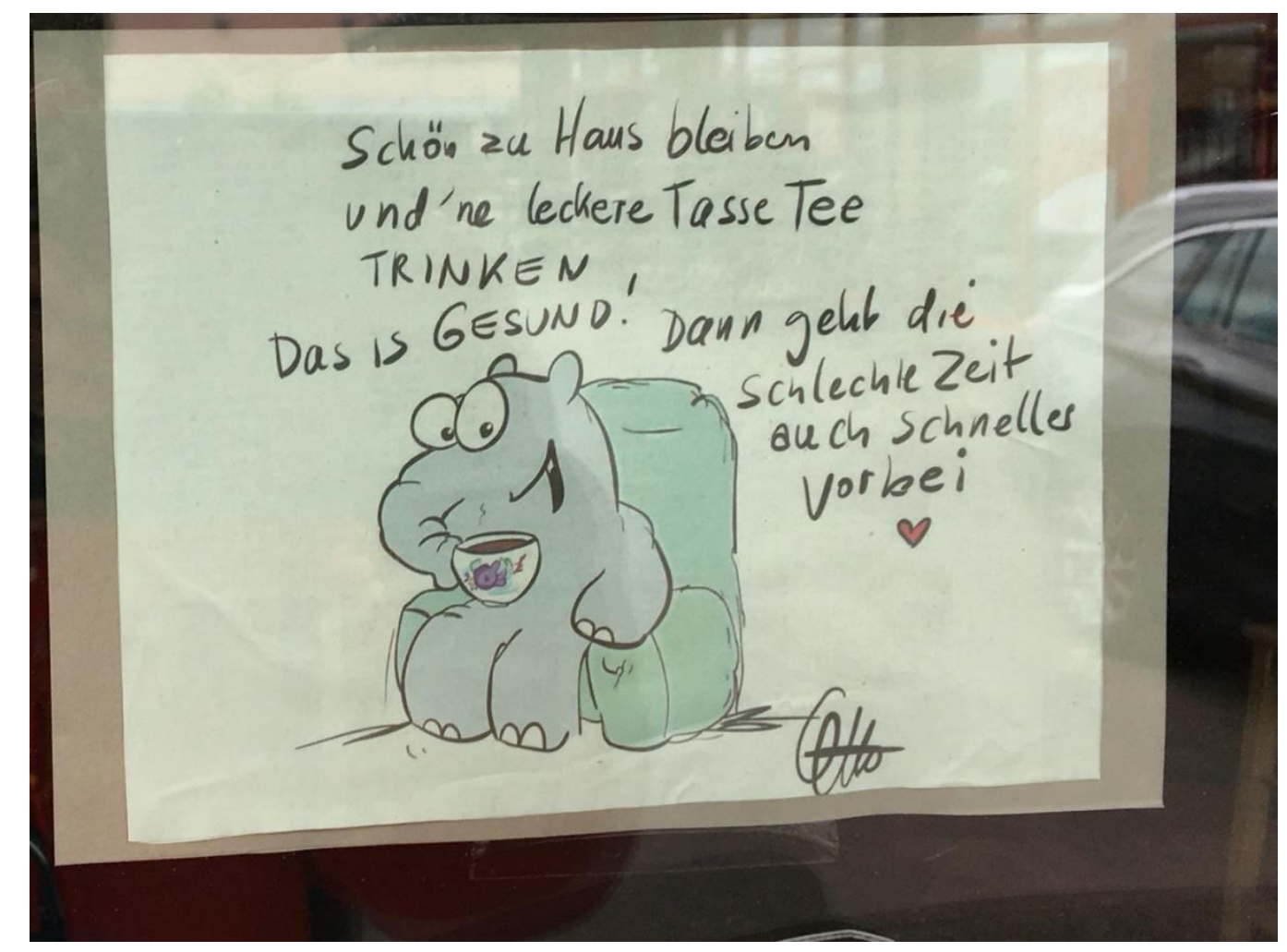

Abbildung 14: Teetrinkender Ottifant (KPK 14.05.2020)

Lokal: In einigen der untersuchten Krummhörn Dörfer entwickelte sich eine ganz eigene Semiotik im Umgang mit der Pandemie und den mit ihr einhergehenden sozialen Einschränkungen. Jahreszeitliche Feste wie zum Beispiel das Abbrennen der Osterfeuer am Vorabend des Ostersonntags oder das Aufstellen eines Maibaums auf dem zentralen Dorfplatz am 30. April sind wichtige Teile des dörflichen Sozialkalenders. Beides musste 2020 ausfallen. In einigen Krummhörn Dörfern waren stattdessen kleinere, private Maibäume in den Vorgärten zu sehen, vor allem im Dorf Freepsum. Hier wurden zudem zahlreiche Kinderzeichnungen von 
Maibäumen in den Fenstern von Privathäusern und des Dorfkindergartens ausgestellt (siehe Abbildungen 15a und $\mathrm{b}$ und 16):
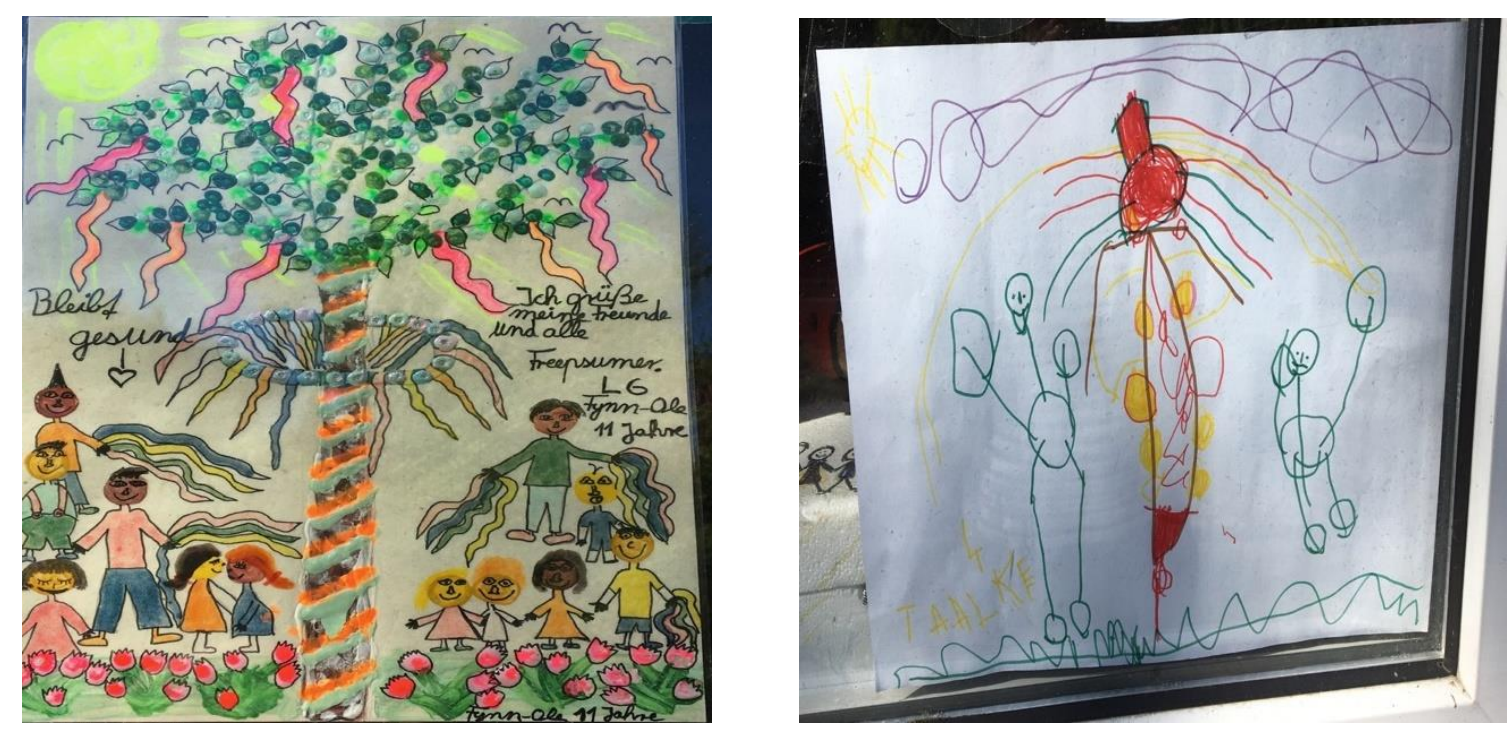

Abbildungen 15a und b: Kinderzeichnungen von Maibäumen (KPK 06.05.2020)

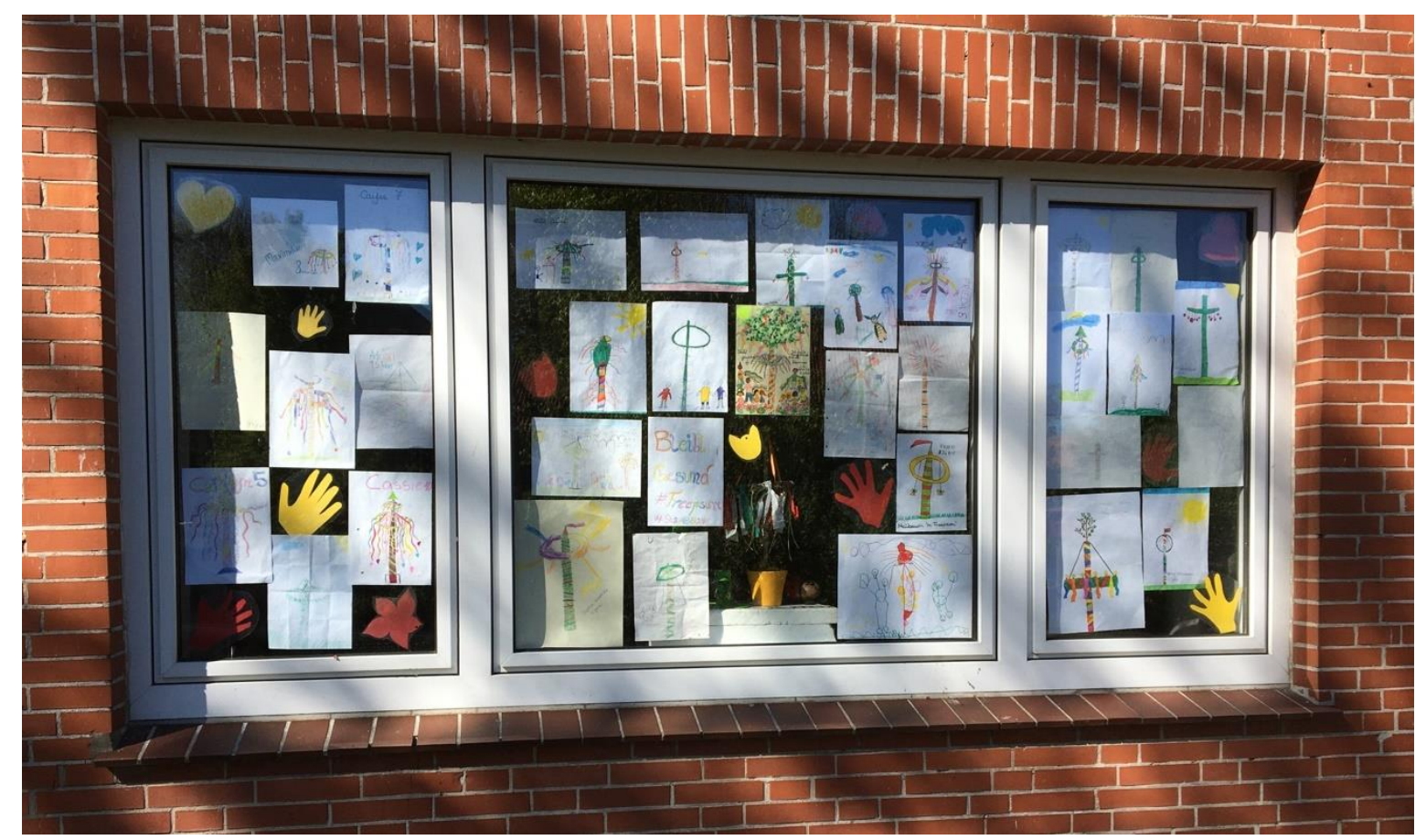

Abbildung 16: Der Dorfkindergarten von Freepsum mit Maibaumzeichnungen (KPK 06.05.2020)

Globale, regionale und lokale Symbole finden sich auch gemischt in einigen komplexeren Displays, wie zum Beispiel den ausgestellten Zeichnungen am vorübergehend geschlossenen Schwimmbad im Zentrum der Krummhörn (siehe Abbildung 17): 


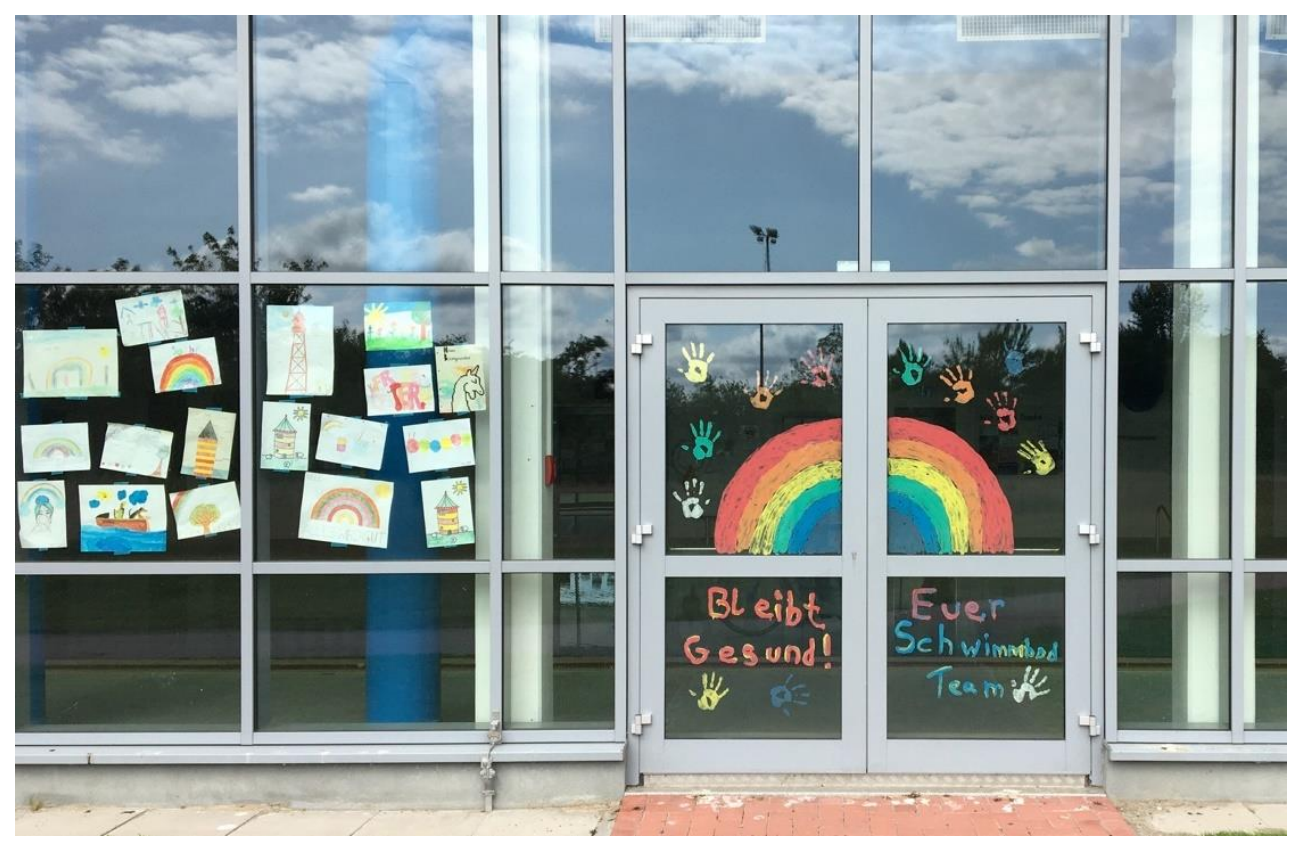

Abbildung 17: Zeichnungen am Schwimmbad (KPK 16.05.2020)

Im ländlichen Untersuchungsraum zeigt sich somit ein Schwerpunkt auf Bildern, wenn es um die Zeichen geht, mit denen man sich in Zeiten der Krise gegenseitig Mut machen will. Dabei handelt es sich um globale, regionale und lokale Bilder von Dingen und Orten, die den Krummhörnern wichtig sind, und um die herum ein Gefühl von Gemeinschaft entstehen kann, das dem Einzelnen vermittelt, dass man angesichts einer globalen Krise nicht allein ist.

Eine besondere Rolle spielt in diesem Symbolkatalog die Regionalsprache Niederdeutsch. Bei den am Schwimmbad ausgestellten Kinderzeichnungen finden sich aufmunternd gemeinte Slogans, die nicht nur auf Deutsch sondern auch auf Englisch und Niederdeutsch verfasst sind. Auch hier verbindet sich das Regionale und Lokale mit dem Globalen (siehe Abbildungen 18a und $b$ ).
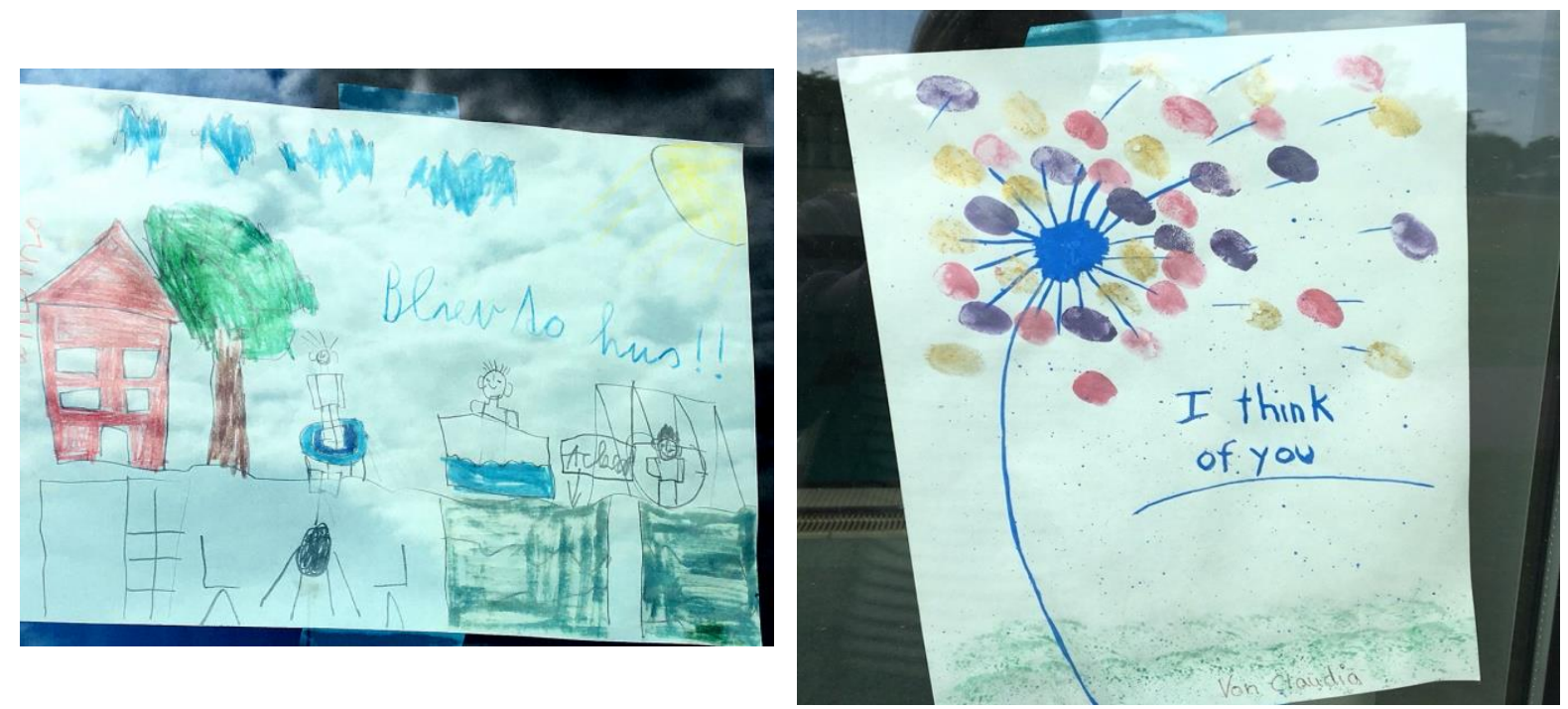

Abbildung 18a und b: Niederdeutsch und Englisch (KPK 16.05.2020) 
In Abbildung 18a hat ein Junge alles gezeichnet, was er an seinem Zuhause schön findet, wie zum Beispiel den Garten, die Schaukel oder das Trampolin. Dies alles macht es dann leichter, während des Lockdowns zu Hause zu bleiben. Den gängigen Pandemie-Slogan „Bleib zu Hause“ hat er ins Niederdeutsche übertragen: „Bliev to hus“. Ein Mädchen namens Claudia hat in Abbildung 18b eine Blume gezeichnet und einen englischen Slogan gewählt: „I think of you“ (,Ich denke an Dich'), vielleicht an Freundinnen und Familienmitglieder gerichtet, die sie unter den Bedingungen des Lockdowns nicht sehen kann.

Das Bild von Julian (siehe Abbildung 19) zeigt das Regenbogenmotiv und einen Slogan, dessen Handschrift vermuten lässt, dass er von einem Erwachsenen hinzugefügt wurde. „Wir schaffen das bleibt gesund" ist eine Kombination des inzwischen etablierten Pandemieslogans und einer von der deutschen Bundeskanzlerin 2015 ausgerufenen Parole, als es um die Aufnahme und Integration einer großen Anzahl von geflüchteten Menschen ging, also aus einer Zeit, die von manchen ebenfalls als krisenhaft bzw. als eine Herausforderung empfunden wurde.

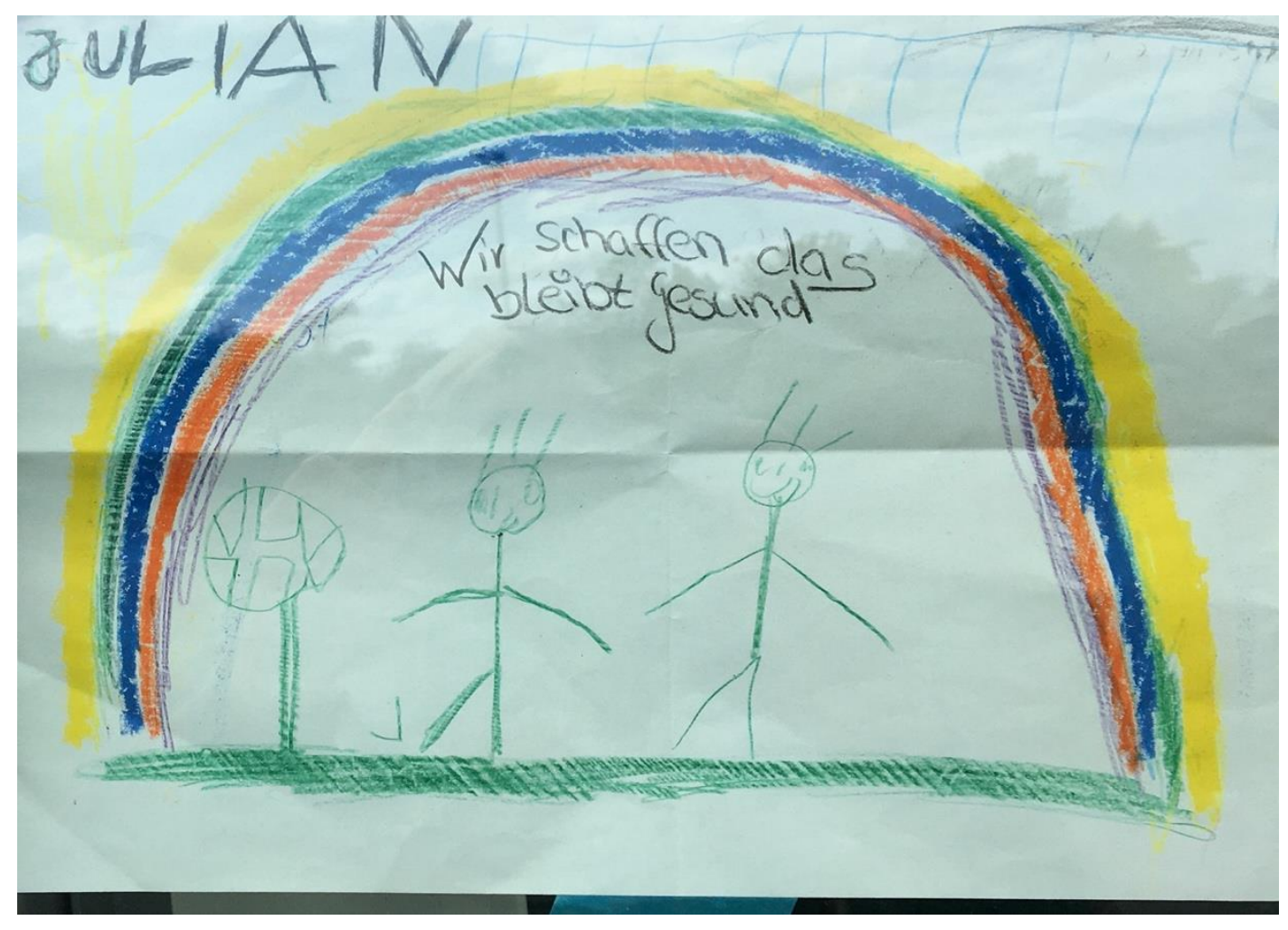

Abbildung 19: Wir schaffen das bleibt gesund (KPK 16.05.2020)

In einem der Krummhörn Dörfer warb eine Schneiderin im Mai 2020 auf Deutsch und Niederdeutsch für die von ihr genähten Schutzmasken (siehe Abbildung 20). Dabei verwendete sie den erst kürzlich und als Reaktion auf die Pandemie entwickelten niederdeutschen Neologismus „Snutenpulli“ (,Schnauzenpulli`). 

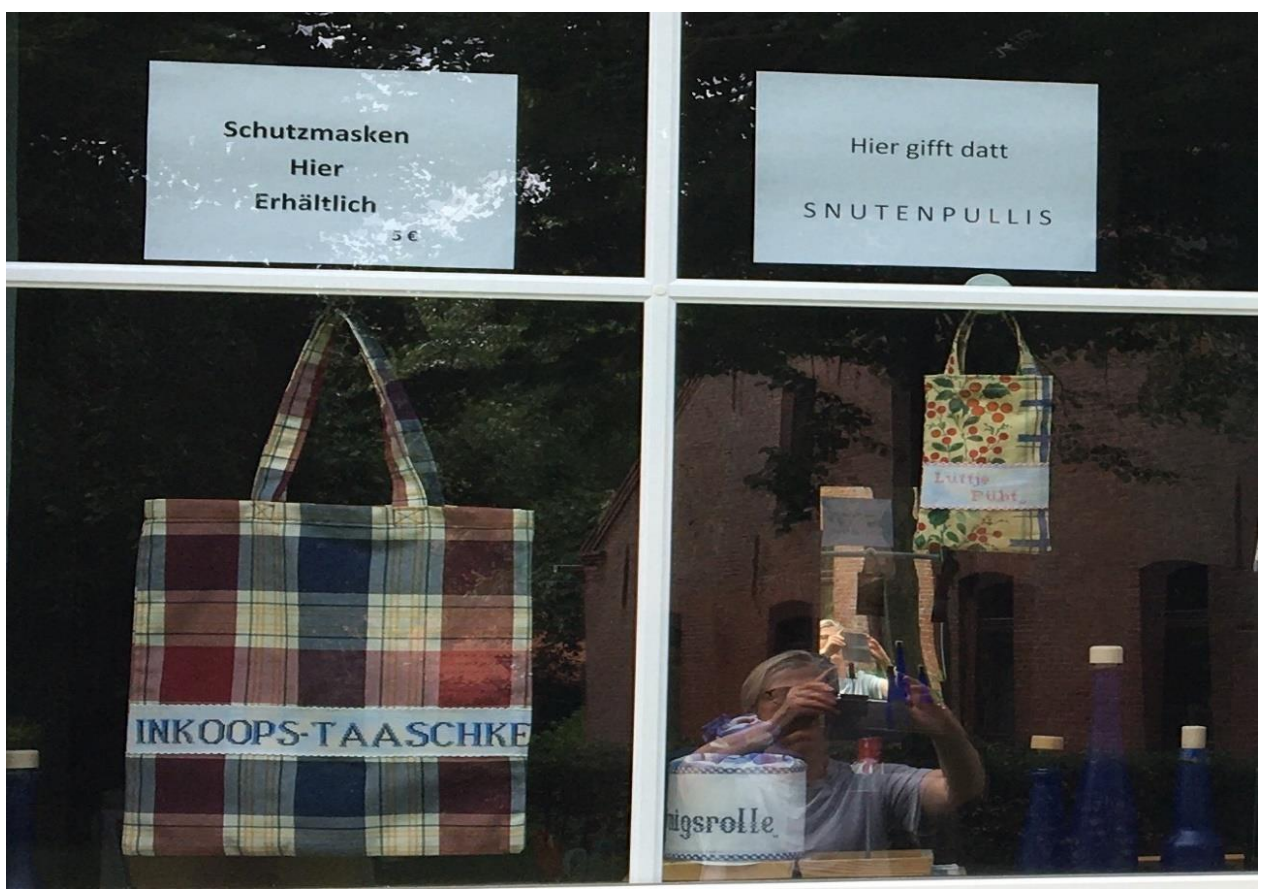

Abbildung 20: Snutenpulli (KPK 11.05.2020)

Die Ostfriesenzeitung veröffentlichte am 29. April 2020 einen Artikel über diesen Neologismus während gleichzeitig Bilder wie in Abbildung 21 in den sozialen Medien die Runde machten:

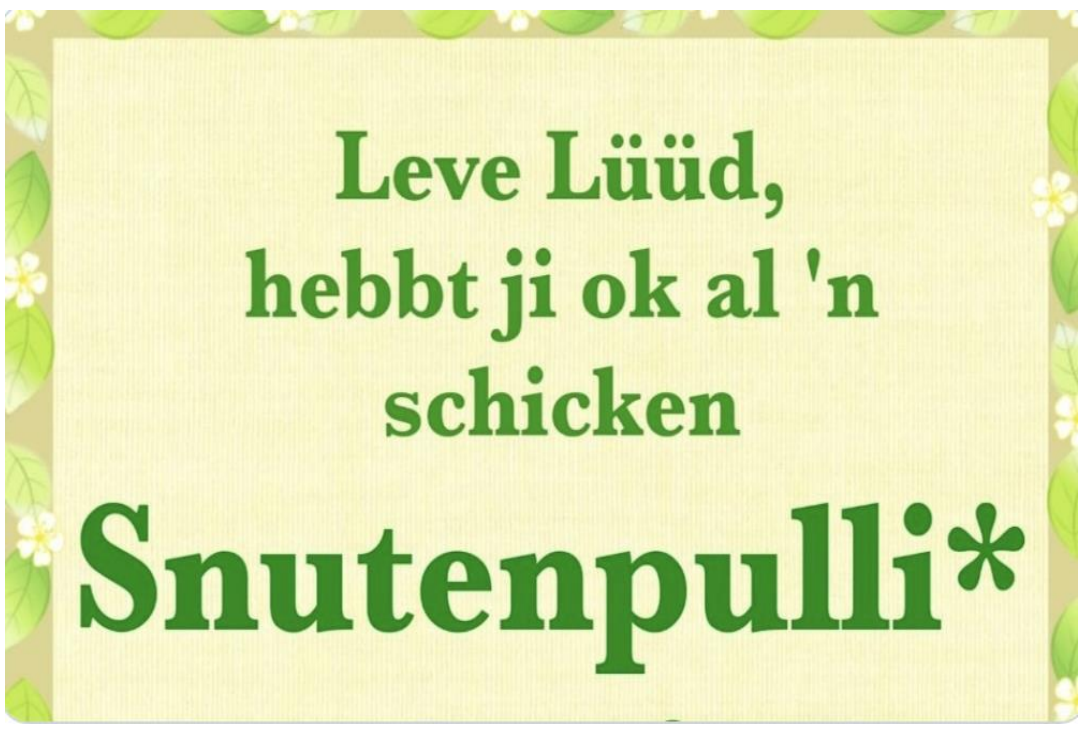

Abbildung 21: Liebe Leute, habt ihr auch schon einen schicken Schnauzenpulli?

Das neue Wort wurde auf diese Art und Weise schnell bekannt, wurde aber von niederdeutschen Sprachaktivisten heftig kritisiert. Sie beanstandeten, dass so viele niederdeutsche Neologismen bestenfalls witzig und schlimmstenfalls krude seien (cf. zum Beispiel das Interview mit dem Direktor des Niederdeutschen Instituts in Bremen in der Ostfriesenzeitung vom 29.04.2020).

Ruhrdeutsche Merkmale finden sich im EPK nur auf zwei Zeichen. Zum einen wird Ruhrdeutsch im Kontext der „Wir sagen Danke“-Plakataktion der Stadt Essen während und nach dem ersten Lockdown verwendet. Wie Abbildung 22 zeigt, fungiert der ruhrdeutsche ,attention 
getter" Hömma ${ }^{13}$ (,hör mal') als regionales Emblem, das gleichermaßen regionale Identität und ein neues regionales Selbstbewusstsein ausdrücken soll. Die Plakataktion spiegelt gleichzeitig die Aufwertung des Ruhrdeutschen und trägt so zur „Adelung“ der ehemals als „Kumpelsprache" stigmatisierten Varietät bei. Zum anderen finden sich ruhrdeutsche Merkmale auch im kommerziellen Kontext. So preist eine Gastwirtschaft im Essener Süden ihr Corona-Pandemie bedingtes To-go-Angebot während des ersten Lockdowns auf einem Aufsteller wie folgt an: „Pommes mit Curry Wurst für aufe Hand oder zum mitnehmen“ (siehe Abbildung 23). Die Präpositionalphrase „für aufe Hand“ mit der Klitisierung von Präposition und bestimmten Artikel ist ein typisches, wenn auch nicht exklusives Merkmal des Ruhrdeutschen. Wie im Metropolenzeichen-Projekt gezeigt werden konnte, ist der Anteil ruhrdeutscher Merkmale in der Linguistic Landscape des Ruhrgebiets mit 4 \% insgesamt sehr niedrig (cf. Ziegler et al. 2018: 56) und betrifft im Wesentlichen die Bereiche Freizeitkultur und Werbung. Insofern überrascht das geringe Auftreten ruhrdeutscher Merkmale im EPK nicht. Die Verwendung von Ruhrdeutsch im Kontext der Corona-Pandemie kann insofern als markiert betrachtet werden, bezieht aber genau daraus seinen Effekt.

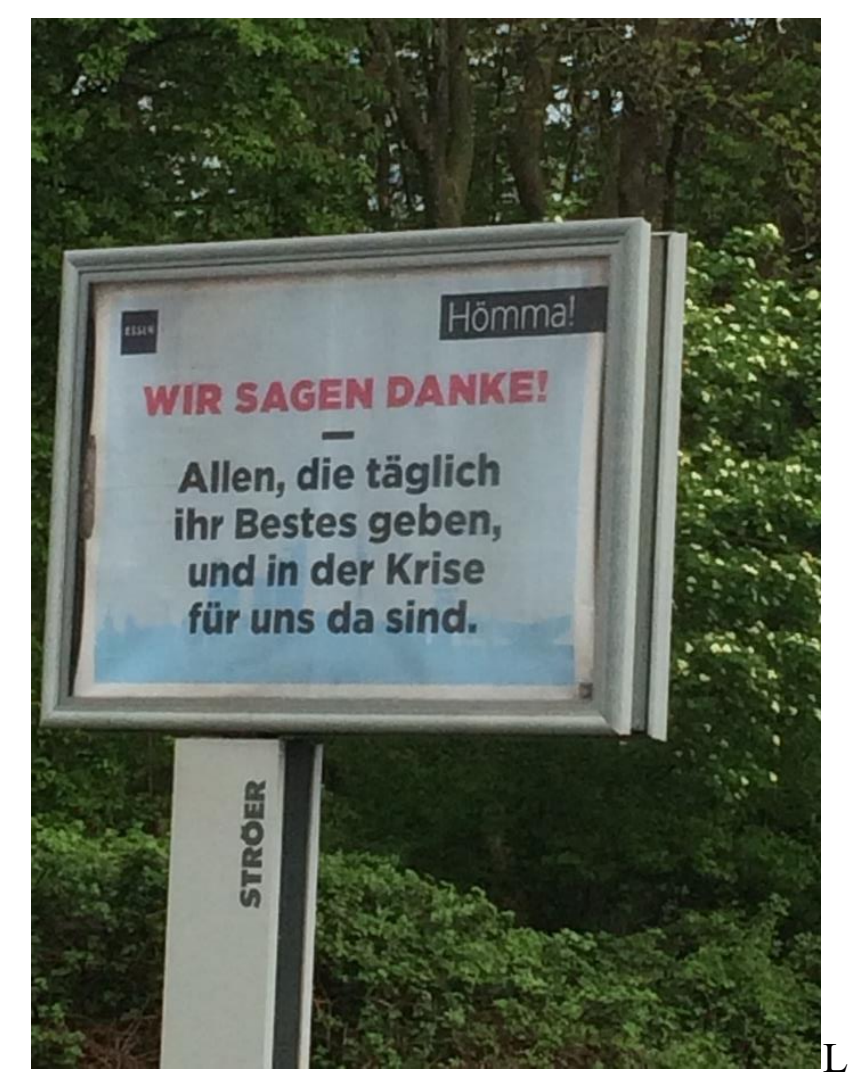

Abbildung 22: Hömma! Wir sagen Danke! (EPK, Bildnummer 0896 - 18.04.2020)

13 CF. dazu auch den Aufsatz von Tophinke/Ziegler (2019b). 


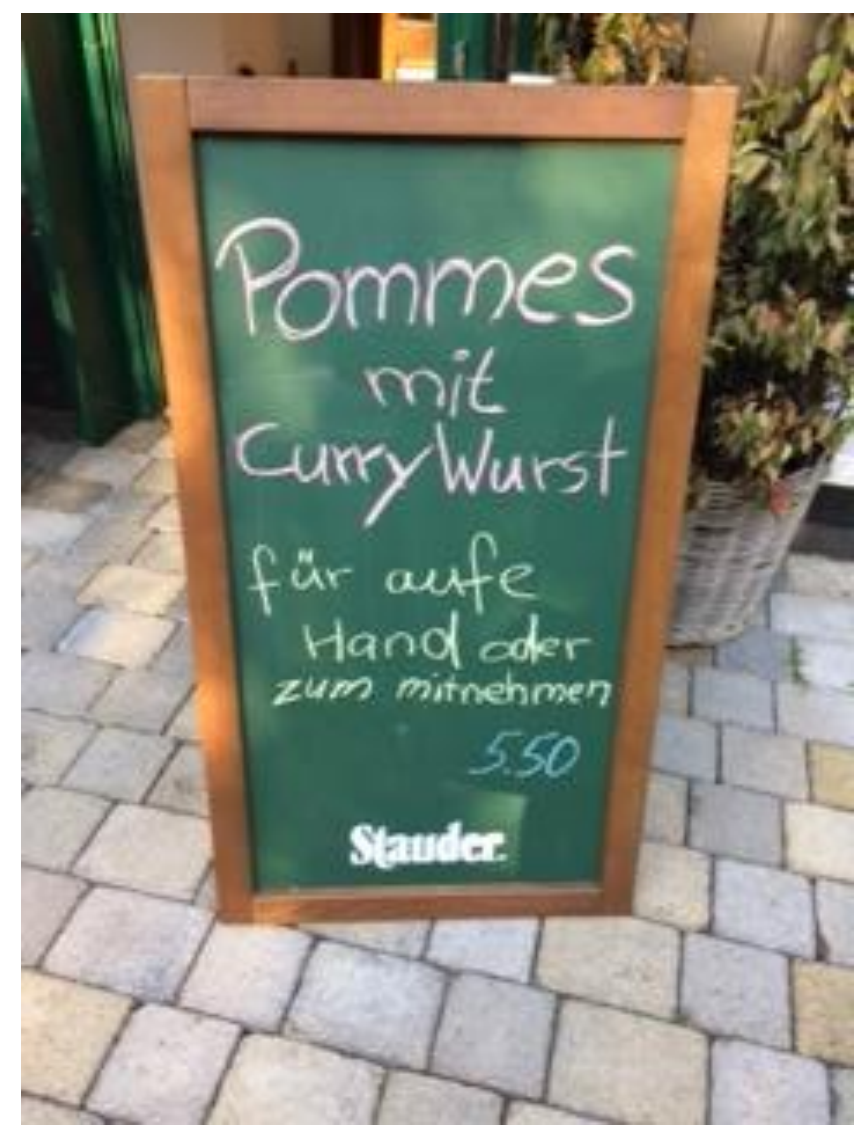

Abbildung 23: Pommes mit Curry Wurst für aufe Hand (EPK, Bildnummer 0705 - 11.04.2020)

Während die affektiven Zeichen, die das Regenbogen- und Sonnenmotiv zeigen, vorwiegend im privaten Bereich verwendet werden, dominieren im kommerziellen Bereich im EPK sprachliche Ausdrucksformen, um Emotionen zu kommunizieren. So begrüßten nach dem ersten Lockdown viele Geschäfte in Essen die Kunden mit Slogans wie „Wir freuen uns, dass Sie da sind!“ (Bildnummer 1229), „Schön, dass Sie wieder da sind“ (Bildnummer 1057), „Good to see you again“ (Bildnummer 1028), „Happy to see you again!“ (Bildnummer 1037), „We take care“ (Bildnummer 1048), „Wir sind bei euch“ (Bildnummer 1041) oder auch „Wir haben dich vermisst und deine Gesundheit ist uns wichtig“ (Bildnummer 1050). Neben dem häufigen Gebrauch von Englisch, der vor allen Dingen für internationale Handelsketten typisch ist, fällt die nähesprachliche Adressierung der Kundschaft auf. Diese Tendenz zu dialogisierter Nähekommunikation (cf. auch das Ikea-Du), bei der die Adressierung der Kunden gewissermaßen den Initial-Turn eines schriftlichen Dialogs ${ }^{14}$ darstellt, hat in der Corona-Pandemie zugenommen ${ }^{15}$ : Die Kunden werden geduzt, und zwar sowohl im Bereich der Kundenansprache (,Wir freuen uns, dich wieder am 11.05. begrüßen zu dürfen“, EPK Bildnummer 1035) als auch im Bereich der Kundenappelle, wie das Beispiel der traditionellen Backstube Malzers (gegründet 1901)

\footnotetext{
${ }^{14} \mathrm{Zu}$ schriftlichen Dialogen im öffentlichen Raum cf. den Aufsatz von Schmitz/Ziegler (2016), in dem die charakteristischen Merkmale sichtbarer Dialoge im öffentlichen Raum herausgearbeitet werden.

15 Diese Entwicklung lässt sich auch an einzelnen Geschäften direkt ablesen. So spricht eine Buchhandlung in Essen-Kettwig auf einem älteren Aushang ihre Kunden mit „Sie“ an („Wir freuen uns auf Sie“, Bildnummer 2600 EPK - 16.01.2021), auf einem aktuellen Aushang dagegen werden die Kunden geduzt: „Wir sind auch weiter für Euch !!!!!!! da !!!!!!! (Bildnummer 2599 EPK - 16.01.2021).
} 
und das Beispiel des Aufstellers vor einem Essener Café zeigen (siehe Abbildungen 24 und 25). Typografisch unterstützt wird die nähesprachliche Kundenansprache in Abbildung 25 durch die Handschrift und die Buchstabenarchitektur, insbesondere die Alternation zwischen Groß- und Kleinschreibung der Kleinbuchstaben, die modern, jugendlich und locker anmutet sowie den Eindruck von Individualismus vermittelt ${ }^{16}$. Die Aufforderung „Seid lieb zueinander“ verstärkt die persönliche Note.

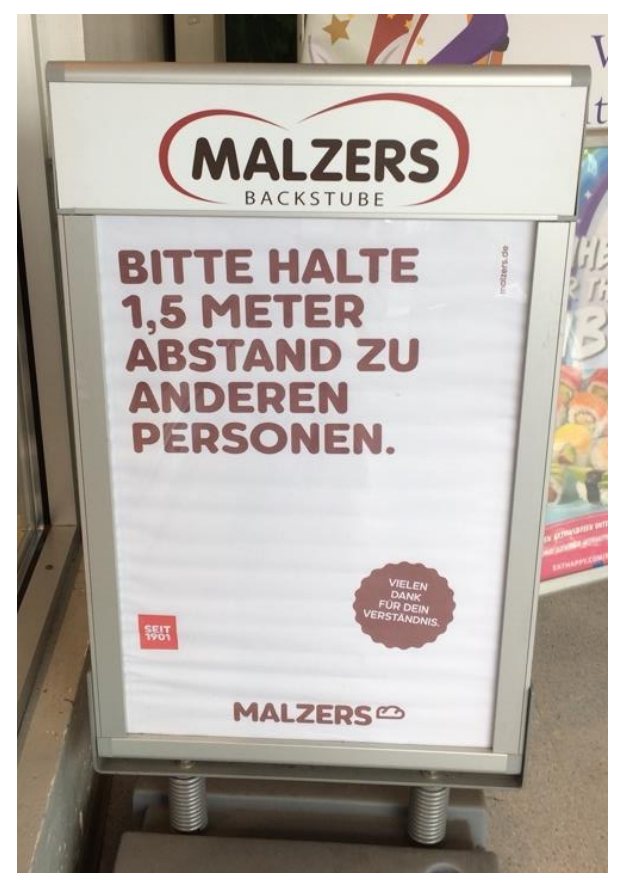

Abbildung 24: Duzen bei Geboten (EPK, Bildnummer 0610 - 27.03.2020)

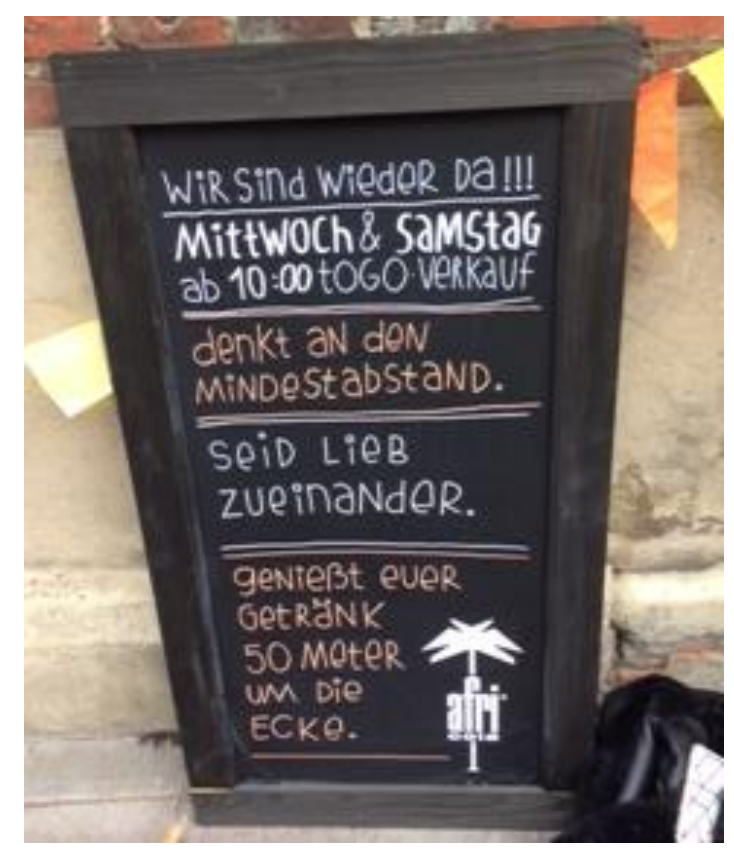

Abbildung 25: Duzen bei Geboten und Appellen (EPK, Bildnummer 1080 - 16.05.2020)

\footnotetext{
${ }^{16}$ Für die Unterstützung bei der Bestimmung der Schriftform bedanken wir uns bei Irmi Wachendorff/DuisburgEssen.
} 
Dort, wo die Kundenansprache formeller ist, dominieren Adressierungen wie „Liebe Kunden“, „Liebe Gäste“ oder auch „Liebe Freunde“ (EPK Bildnummer 0845). Kontextsensitiv soll so in der Krisenzeit Verbundenheit ausgedrückt, eine emotionale und solidarische Beziehung zum Kunden aufgebaut und das Firmenimage positiv gestärkt werden. Eine besondere Form der sichtbaren dialogischen Kommunikation mit den Kunden stellt Abbildung 26 dar. Hier wird die Ankündigung der Wiedereröffnung eines Friseurgeschäfts in Essen-Werden nach dem ersten Lockdown als eine persönliche Mitteilung der Bundeskanzlerin inszeniert. Dabei wird redeeinleitend mit dem Vornamen auf die Bundeskanzlerin referiert: „Angela sagt“". In direkter Rede heißt es dann ebenso lapidar wie schnörkellos: ,ab Montag, den 4. Mai hat Hartmann wieder auf".

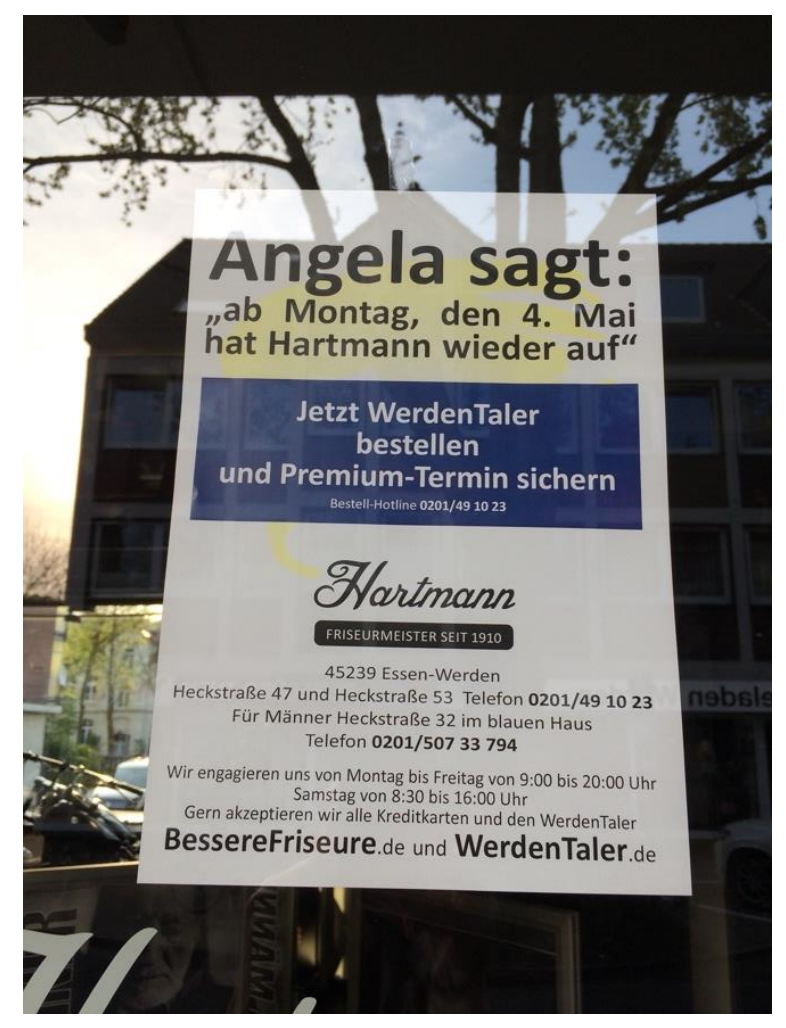

Abbildung 26: Angela sagt (EPK, Bildnummer 0772 - 16.04.2020)

Die Orientierung auf das Regionale und Lokale in der Krummhörn (,Verehrte Krummhörnerinnen und Krummhörner") wird im urbanen Raum ersetzt durch eine Orientierung auf das Soziale, indem die Essener Stadtgemeinschaft als eine heterogene und internationale ,Wir-Gemeinschaft" (cf. Tietz 2002) angesprochen wird, wie die Plakataktion des Citymanagements zeigt, bei der die Adressaten mit dem inkludierenden Personalpronomen ,wir“ angesprochen werden: „Wir! Zusammen gegen das Virus. \#essenhältzusammen“ (Bildnummer 0885, 0892). Diese Aktion ${ }^{17}$ fand während des ersten Lockdowns statt. Die Plakate wurden fast ausnahmslos in den Stadtteilen im Essener Norden, zu dem der Untersuchungsstadtteil Altenessen und die Innenstadt gehören, aufgestellt, nicht jedoch in den Stadtteilen im Essener Süden, zu denen

\footnotetext{
17 Siehe in diesem Zusammenhang auch die Kampagne des Ministeriums für Kinder, Familie, Flüchtlinge und Integration (MKFFI) des Landes Nordrhein-Westfalen, in der es heißt: \#IchDuWirNRW, Fernsehmoderatorin Nazan [Eckes]: „Zusammenhalt bedeutet: Schutz und Selbstschutz. Für dich. Für uns.“ Das Plakat ist ausschließlich im Essener Norden zu sehen (Bildnummer 1242).
} 
Kettwig und Werden zählen. Erklären lässt sich dieser Befund damit, dass die Zahlen der Corona-Infizierten und Toten in den Stadtteilen nördlich der A 40 signifikant höher waren (und immer noch sind) als in den Stadtteilen südlich der A 40 und insofern ein klares Nord-SüdGefälle zeigen, das sich in einem erhöhten $\mathrm{Ma}$ an Solidaritätsaufrufen und „GemeinschaftsExpressiven“ (Janich 2020: 117) in den Stadtteilen des Essener Nordens widerspiegelt. Die Demonstration von Einigkeit kommt dabei vor allen Dingen über die Hochwertwörter ,Zusammenhalt" und „Gemeinschaft“ (Bildnummer 0888, 1242 und 1041, EPK) zum Ausdruck, die an die solidarische Verantwortung jedes Einzelnen appellieren und ihn als Mitglied einer „Verantwortungsgemeinschaft“" (Etzioni 1997) ansprechen sollen. Die gezielte Kampagne der Stadtverwaltung setzt „Wir“ in diesem Zusammenhang ein, um eine imaginierte solidarische Gemeinschaft zu evozieren, die sich idealerweise in eine reale verwandeln soll, deren Mitglieder sich angesichts der Krise verantwortungsvoll an die Vorsichtsmaßnahmen halten und sich so gegenseitig schützen. Das quantitativ intensivere Emplacement solcher Zeichen im ethnisch und kulturell heterogeneren Norden der Stadt Essen zeigt dabei gleichzeitig eine soziale Differenzierung, die die städtische „Wir-Gemeinschaft“ im Gegenzug zu der beschworenen Verantwortungsgemeinschaft unterläuft.

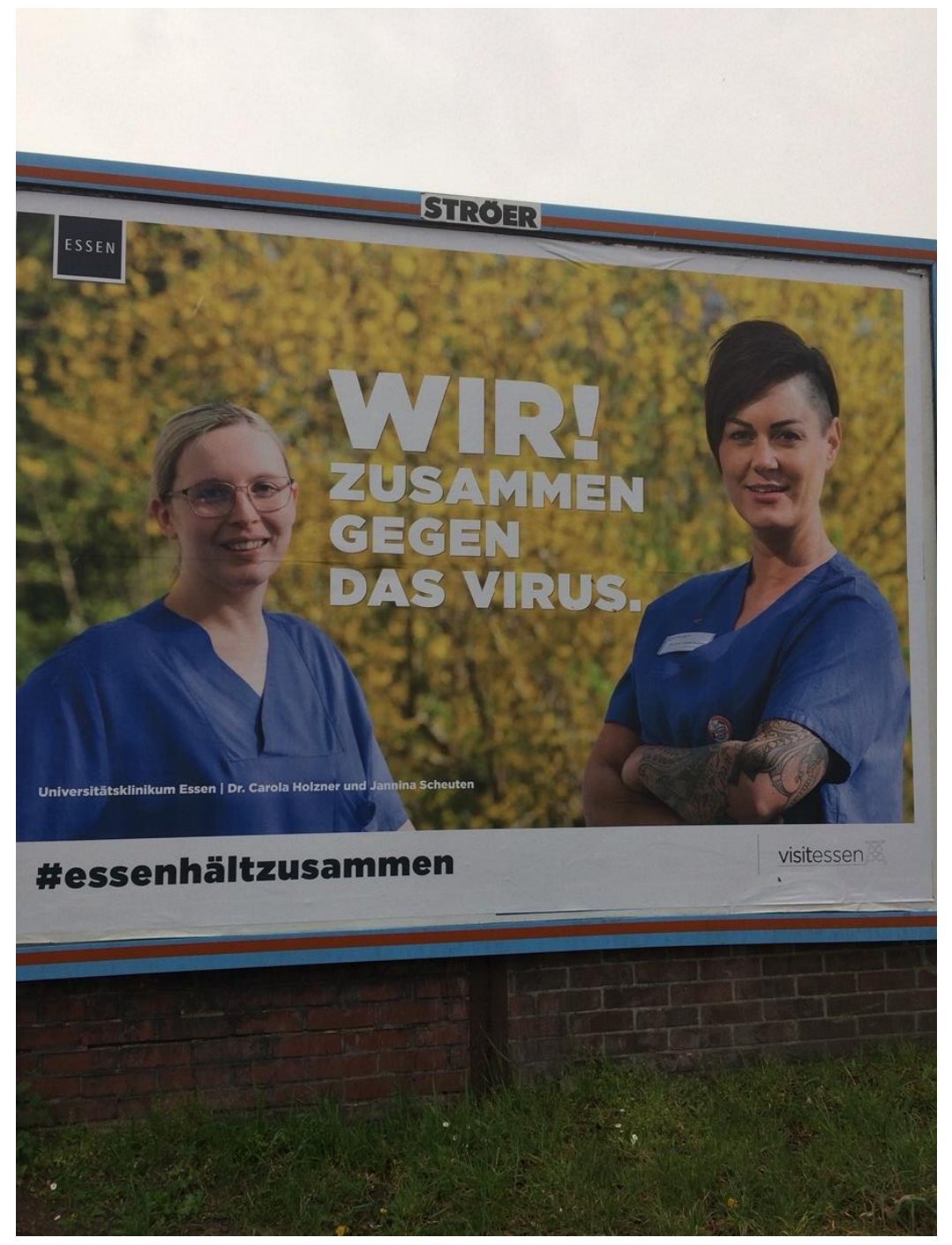

Abbildung 27: Wir! Zusammen gegen das Virus. (EPK, Bildnummer 0892 - 18.04.2020) 


\subsection{Coronamaßnahmen-kritische Zeichen im EPK}

Parallel zur Entwicklung der Corona-Pandemie formiert sich auch Kritik an den Maßnahmen und Beschränkungen, die vor allen Dingen in den Großstädten sichtbar wird, so etwa auf den Demonstrationen in Berlin (17.11.2020) und Leipzig (22.11.2020), aber auch auf illegalen Demonstrationen, wie zum Beispiel am 09. Mai 2020 in Essen, wo sich Demonstranten an der Gruga $^{18}$ versammelten und dann Richtung Hauptbahnhof gelaufen sind. Die Spuren dieses Protestes sind auf einem Trafohäuschen in der Gruga und auf der Kettwiger Straße, der Haupteinkaufsstraße in Essen, in Form von Graffitis zu sehen. Das Herstellen von Graffitis stellt eine Praxis dar, die „die Stadt nicht nur als Aktionsraum nutzt, sondern die zur Konstruktion des städtischen Raumes selbst wesentlich beiträgt“" (Tophinke 2016: 411) und damit konstitutiv für den urbanen Raum ist. Mit den mit einem Filzstift mittig auf den Türen eines Trafohäuschens geschriebenen Verbalgraffitis „Wiederstand (sic!) gegen Merkel-Diktatur!“ und „NUR SKLAVEN tragen Mundschutz!“ (siehe Abbildungen 29 und 30) richtet sich der Protest gegen eine gefühlte faschistische Regierungsform, genauer gegen die „Merkel-Diktatur“, ein Kampfbegriff, der auch auf der Demonstration in Berlin am 17.11.2020 benutzt wurde und der mittlerweile zum Standardrepertoire der Corona-Leugner und Querdenker avanciert ist. Mit der Äußerung „NUR SKLAVEN tragen Mundschutz!“ positioniert sich der Writer gegen die Maskenpflicht und bedient sich dabei eines historischen Vergleichs, der Assoziationen zur Kolonialpolitik, i. e. zur Máscara de flandres herstellt, einer Maske zur Folter von Sklaven im kolonialen Brasilien ${ }^{19}$. Mikrotypografisch, i. e. auf der Ebene der Lesbarkeit und der Formdetails, fallen die Schriftzüge durch die Verwendung von Ausrufezeichen und Versalien auf, beides Mittel, die der Markierung der Aussage, Träger von Mund-Nase-Schutzmasken seien Opfer einer Diktatur, dienen. Anders als die Schriftzüge auf dem Trafohäuschen ist das Kreidegraffiti mit dem verschwörungsideologischen Schlagwort „Coronalüge“, das in Versalienschreibung auf den Pflastersteinen der Kettwiger Straße (siehe Abbildung 31) in unmittelbarer Nähe des Hauptbahnhofs angebracht ist, als Ausdruck des Protests wesentlich auffälliger. Es birgt aber nicht das Risiko der Strafverfolgung, denn es ist nicht dauerhaft sichtbar, da es nicht witterungsbeständig ist, und es ist auch nicht auf/an privatem Eigentum angebracht. Es spiegelt aber eine Praxis wider, die sowohl in der Writer-Szene als auch im Guerilla-Marketing üblich ist und entfernt ex negativo an die in der Corona-Pandemie in Mode gekommenen Kreidezeichnungen mit aufmunternden Parolen erinnert.

Als „Dokumente gesellschaftspolitischer Positionierungen“ (Wachendorff/Ziegler/Schmitz 2017: 157) zeigen die Anti-Corona-Maßnahmen-Graffitis wie mit unterschiedlichen Formen der Situierung der Texte im öffentlichen Raum (Trafohäuschen im Park; Pflastersteinaufschrift in einer Einkaufsstraße) unterschiedliche Adressatengruppen angesprochen werden können, etwa Spaziergänger (siehe Abbildungen 28 und 29) oder Arbeitspendler und Konsumenten (siehe Abbildung 30). Der städteräumliche Kontext prägt so auch die Wahrnehmung und Wirkung der Corona-Pandemie kritischen Positionierungen.

\footnotetext{
18 Gruga: Abkürzung für Grugapark, ein städtischer Park in Essen, der zur Gartenbau-Ausstellung 1929 angelegt wurde.

${ }^{19}$ Siehe dazu ausführlicher Wikipedia, s. v. Máscara de flandres.
} 


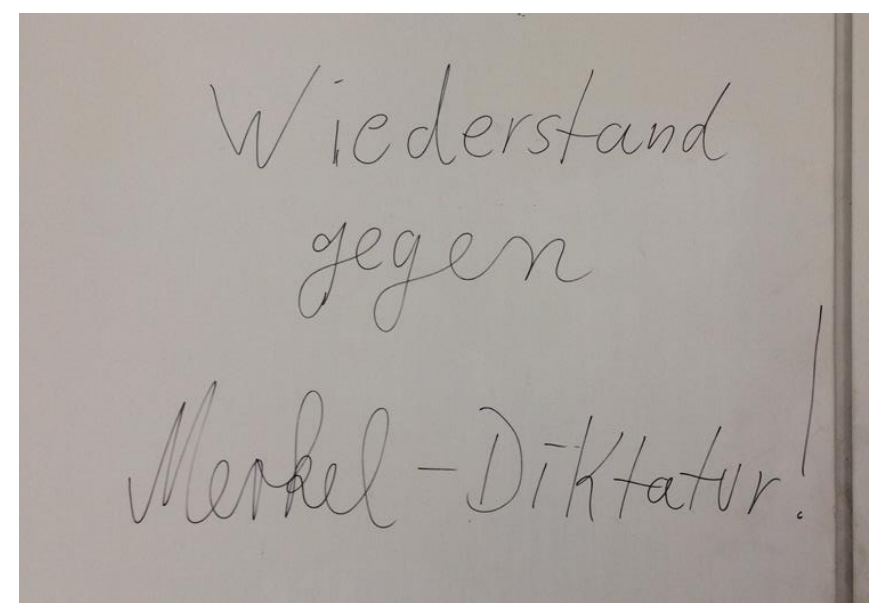

Abbildung 28: Wiederstand gegen Merkel-Diktatur (EPK, Bildnummer 1993 - 26.09.2020)

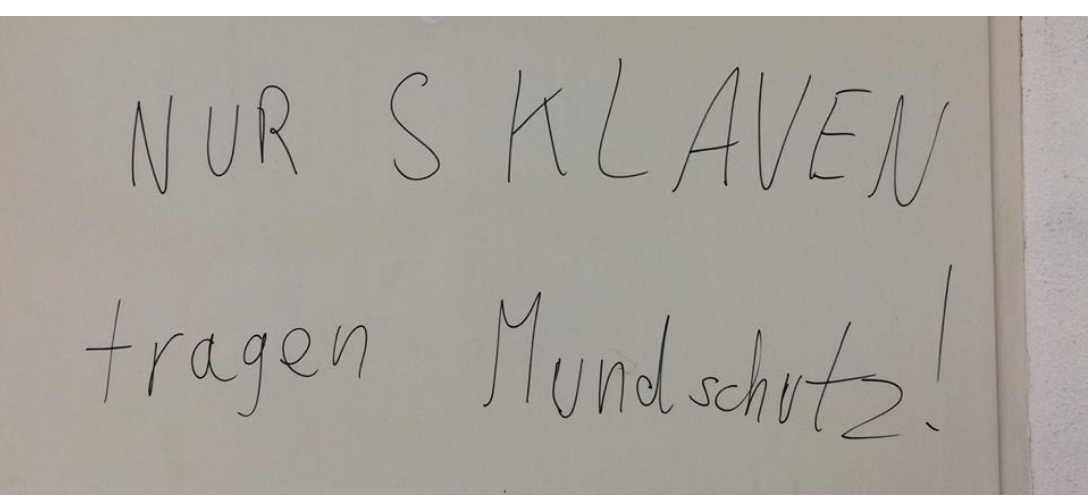

Abbildung 29: Nur Sklaven tragen Mundschutz! (EPK, Bildnummer 1992 - 26.09.2020)

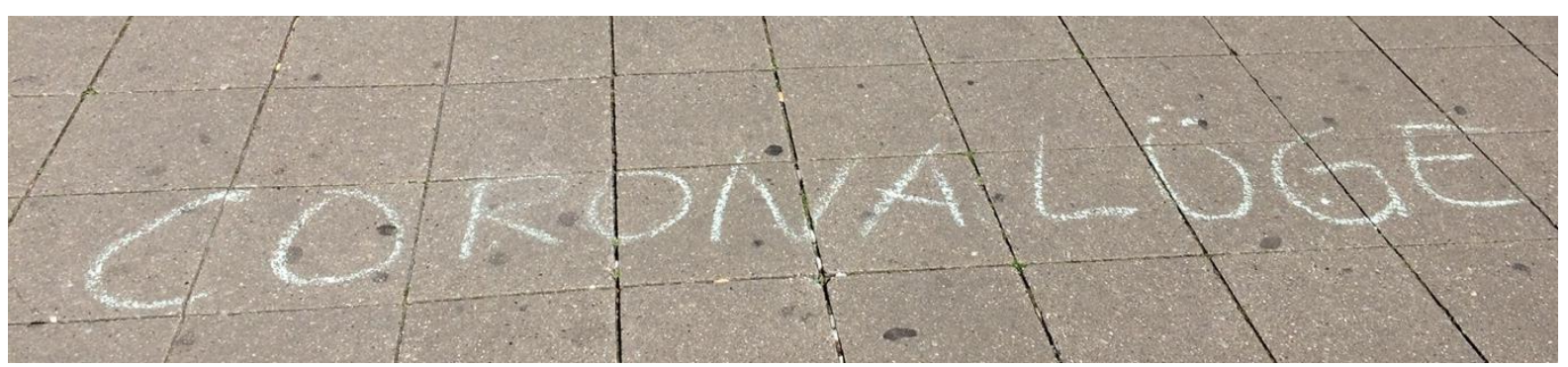

Abbildung 30: Coronalüge (EPK, Bildnummer 1020 - 11.05.2020)

\section{Schlussfolgerungen}

Die vorliegende Studie hatte es sich zum Ziel gemacht, zu untersuchen, wie Menschen angesichts einer globalen Krise den öffentlichen Raum (um)gestalten. Die Analyse hat gezeigt, dass sowohl in der Stadt als auch im ländlichen Raum die regulatorischen Zeichen quantitativ dominieren, die den sich in diesen Räumen aufhaltenden Menschen die neuen Gegebenheiten des sozialen Miteinanders zeigen und zum Teil erklären. Ein überraschender Befund ist der relativ große Anteil affektiver Zeichen in beiden Korpora. In den Dörfern der Krummhörn sind affektive Zeichen mit $27 \%$ etwas stärker vertreten als in der Stadt Essen (16\%). In beiden Untersuchungsräumen wurden affektive Zeichen vorzugsweise an der Grenzfläche zwischen Vorderund Hinterbühne, i. e. an Fenstern, Türen oder in Gärten von Privathäusern und -wohnungen platziert, wo öffentlicher Raum und Wohnraum ineinander übergehen. 
Trotz dieser Gemeinsamkeiten zeigen sich in der Detailanalyse auch Unterschiede zwischen den ländlichen und städtischen Untersuchungsräumen. Coronamaßnahmen-kritische Zeichen konnten im ländlichen Untersuchungsraum nicht festgestellt werden, in der Stadt Essen machten sie $2 \%$ der Gesamtdaten aus. Affektive Zeichen, wie sie für beide Korpora gesammelt werden konnten, haben die Funktion, angesichts einer Bedrohung wie der Corona-Pandemie die Stärke der Gemeinschaft und ihre Resilienz zu beschwören. Im ländlichen Raum wird dies insbesondere mit bildlichen Mitteln getan, indem auf kollektive regionale Symbole wie zum Beispiel Leuchttürme, Windmühlen etc. rekurriert wird. Diese Zeichen wurden durchweg bottom-up von den Dorfbewohnern selbst produziert und angebracht. Im urbanen Untersuchungsraum wird die Gemeinschaft vor allem mit sprachlichen Mitteln betont, indem zum Beispiel das Kollektivpronomen wir wiederholt eingesetzt wird. Hierbei handelt es sich jedoch um eine top-down-Initiative der Essener Stadtverwaltung. Das Pronomen wir (cf. Brewer/Gardner 1996) betont die Gemeinsamkeiten der städtischen Gemeinschaft mit der impliziten Botschaft, dass angesichts der Bedrohung durch die Pandemie alle in derselben Situation und somit vor dem Virus gleich sind. In appellativer Funktion wird mit dem Pronomen wir die gesamte Stadtgemeinschaft adressiert und damit zu Solidarität, i. e. sozialem Verantwortungsbewusstsein, aufgefordert, indem zum Ausdruck gebracht wird, dass der Schutz der Gemeinschaft auch dem Schutz der eigenen Person dient. Die gezielte Verwendung des Pronomens wir erzeugt demzufolge eine diskursive Realität, eine ,imaginierte Gemeinschaft“ (Anderson 1983), die angesichts der Krise zu einer realen werden könnte.

Regionalsprachliche Merkmale werden in beiden Korpora als markierte Formen mit kollektivsymbolischer Bedeutung eingesetzt. Im ländlichen Untersuchungsgebiet der Krummhörn kommen regionalsprachliche Merkmale quantitativ häufiger und in größeren syntaktischen Einheiten vor. Sie werden als Teil eines regionalen Symbolkatalogs eingesetzt, der das umfasst, was den Menschen in diesem Raum als Zeichen gemeinsamer Identität zur Verfügung steht und was auf diese Art und Weise eine Gemeinschaft konstruiert, in die sich der Einzelne in Zeiten der Krise eingebunden fühlen kann. Im urbanen Untersuchungsraum, i. e. in der Stadt Essen, sind regionalsprachliche Zeichen dagegen die Ausnahme, aber dadurch besonders salient, wenn sie verwendet werden. Ihr Gebrauch deutet darauf hin, dass die ehemals als „Kumpelsprache“ apostrophierte regionale Varietät ihr soziales Stigma verloren hat. Im Zuge dieses Umwertungsprozesses werden Merkmale wie „Hömma“ als allgemein regionalsprachlich definiert. Bücher wie Hömma! Sprache im Ruhrgebiet von Claus Sprick (2009) oder Langenscheidt Ruhrdeutsch für Anfänger von Bruno „Günna“ Knust (2019)20, die sich an Einheimische, Zugezogene und Touristen richten, popularisieren und inszenieren die entsprechenden Formen als ruhrdeutsch. So rekontextualisiert, können ruhrdeutsche Merkmale zur kulturellen Konstruktion von Gemeinschaft im Ruhrgebiet herangezogen werden.

\section{Literaturverzeichnis}

Adler, Astrid et al. (2016): Status und Gebrauch des Niederdeutschen. Erste Ergebnisse einer repräsentativen Erhebung. Mannheim: Institut für Deutsche Sprache und Institut für Niederdeutsche Sprache.

${ }^{20}$ Bruno „Günna“ Knust ist der ehemalige Stadionsprecher des BVB Dortmund. 
Anderson, Benedict (1983): Imagined Communities. Reflections on the Origins and Spread of Nationalism. London: Verso.

Androutsopoulos, Jannis (2020): „Die Sprachlandschaft im Dispositiv der Pandemie“. Corona. Essayistische Notizen zum Diskurs: 290-299. (= Aptum. Zeitschrift für Sprachkritik und Sprachkultur 16/2-3.)

Auer, Peter (2010): „Sprachliche Landschaften. Die Strukturierung des öffentlichen Raums durch die geschriebene Sprache“. In: Deppermann, Arnulf/Linke, Angelika (eds.): Sprache intermedial. Stimme und Schrift, Bild und Ton. Berlin/New York, de Gruyter: 271-298. (= Jahrbuch des Instituts für Deutsche Sprache 2009).

Auer, Peter/Schmidt, Jürgen (eds.) (2010): Language and Space. An International Handbook of Linguistic Variation. Theories and Methods. Berlin/New York: Mouton de Gruyter.

Blommaert, Jan (2013): Ethnography, Superdiversity and Linguistic Landscapes: Chronicles of Complexity. Bristol: Multilingual Matters.

Brewer, Marilynn B./Gardner, Wendi (1996): "Who is this 'We'? Levels of collective identity and self representations". Journal of Personality and Social Psychology 71/1: 83-93.

Britain, David (2017): "Which way to look? Perspectives on ,urban' and ,rural' dialectology". In: Moore, Emma/Montgomery, Chris (eds.): Language and a sense of place: Studies in Language and Region. Cambridge, CUP: 171-187.

Chambers, Jack K./Trudgill, Peter (1998/2012): Dialectology. Cambridge: CUP.

Cloke, Paul (2006): "Conceptualizing rurality". In: Cloke, Paul/Marsden, Terry/Mooney, Patrick (eds.): Handbook of Rural Studies. London, Sage: 18-28.

De Certeau, Michael (1988/2006): „Praktiken im Raum“. In: Dünne, Jörg/Günzel, Stephan (eds.): Raumtheorie. Grundlagentexte aus Philosophie und Kulturwissenschaften. Frankfurt a. M., Suhrkamp: 343-353.

Deppermann, Arnulf (2006): „Deontische Infinitivkonstruktionen: Syntax, Semantik, Pragmatik und interaktionale Verwendung“. In: Günthner, Susanne/Imo, Wolfgang (eds.): Konstruktionen in der Interaktion. Semantik, Pragmatik und interaktionale Verwendung. Berlin/New York, de Gruyter: 239-262.

Dittmar, Norbert/Schlieben-Lange, Brigitte (1982): „Stadtsprache. Forschungsrichtungen und -perspektiven einer vernachlässigten soziolinguistischen Disziplin“. In: Bausch, Karl-Heinz (ed.): Mehrsprachigkeit in der Stadtregion. Jahrbuch 1981 des Instituts für deutsche Sprache. Düsseldorf, Schwann: 9-86.

Eckert, Penelope (2010): "Who's there? Language and space in social anthropology and interactional sociolinguistics”. In: Auer, Peter/Schmidt, Jürgen (eds.): Handbook of language and space. Berlin/NewYork, Mouton de Gruyter: 163-178.

Eckert, Penelope (2012): "Three waves of variation study. The emergence of meaning in the study of variation". Annual Review of Anthropology 41: 87-100.

Essen.de: „Bevölkerungsstatistik zum Jahresende 2019: Wie erwartet nur leichtes Bevölkerungswachstum". essen.de/meldungen/pressemeldung_1353169.de.html. [05.10.2021].

Etzioni, Amitai (1997): Die Verantwortungsgesellschaft. Individualismus und Moral in der heutigen Demokratie. Frankfurt a. M.: Campus-Verlag.

Gilles, Peter/Ziegler, Evelyn (2019): „Linguistic Landscape-Forschung in sprachhistorischer Perspektive: öffentliche Bekanntmachungen in der Stadt Luxemburg im langen 19. Jahrhundert“. Zeitschrift für germanistische Linguistik 47/2: 385-407. 
Goffman, Erving (1959/2003): Wir alle spielen Theater. Die Selbstdarstellung im Alltag. München: Piper.

Halfacree, Keith (2006): "Rural space: constructing a threefold architecture". In: Cloke, Paul/Marsden, Terry/Mooney, Patrick (eds.): Handbook of Rural Studies. London, Sage: 4462.

Harding, Alan/Blokland, Talja (2014): Urban theory: A critical introduction to power, cities and urbanism in the 21stcentury. London: Sage.

Hoggart, Keith (1990): "Let's do away with rural”. Journal of Rural Studies 6: 245-257.

Interview mit dem Direktor des Niederdeutschen Instituts in Bremen in der Ostfriesenzeitung vom 29.04.2020. m.facebook.com/Wachholtz.Plattdeutsch/photos/a.224406684259893/ $3259985380701993 /$ ?type $=3 \&$ source $=48 \&$ tn_ $=$ EH-R [11.10.2021.]

Janich, Nina (2020): „Hamsterkäufe, Kontaktverbot und Bürgerrecht. Ein sprachkritisches Gedicht inmitten der Corona-Zeit (März 2020)“. Corona. Essayistische Notizen zum Diskurs: 114-119. (= Aptum. Zeitschrift für Sprachkritik und Sprachkultur 16/2+3.)

Jaworski, Adam/Thurlow, Chrispin (2010): „Introducing Semiotic Landscapes“. In: Jaworski, Adam/Thurlow, Chrispin (eds.): Semiotic Landscapes: Language, Image, Space. London, Bloomsbury: 1-40.

Johnstone, Barbara (2013): Speaking Pittsburghese. The Story of a Dialect. Oxford: OUP.

Kamwangamalu, Nkonko M./Tovares, Alla V. (2019): "Urban and rural language contact". In: Darquennes, Jacques/Salmons, Joseph S./Vandenbussche, Wim (eds.): Language Contact. An International Handbook Vol. 1: Berlin/Boston, Mouton de Gruyter: 310-332.

Kersting, Volker et al. (2009): „Die A40 - Der ,Sozialäquator“ des Ruhrgebietes“. In: Prossek, Achim et al. (eds.): Atlas der Metropole Ruhr. Vielfalt und Wandel des Ruhrgebiets im Kartenbild. Essen, Emons Verlag: 142-145.

Klug, Nina-Maria/Pappert, Steffen (2020): „Wenn Rasen tötet und Prägnanz fordert. Merkmale multimodaler Texte an der Autobahn“. In: Berdychowska, Zofia/Liedtke, Frank (eds.): Prägnante Kürze und mehr. Kurztexte und multimodale Kurzformen im öffentlichen Raum. Frankfurt a. M.: Lang: 147-160.

Knust, Bruno (2019): Langenscheidt Ruhrdeutsch für Anfänger. München: Langenscheidt.

Löw, Martina (2001): Raumsoziologie. Frankfurt a. M.: Suhrkamp.

Muth, Sebastian (2015): "Language removal, commodification and the negotiation of cultural identity in Nagorno-Karabakh". In: Rubdy, Rani/Ben Said, Selim (eds.): Conflict, exclusion and dissent in the linguistic landscape. Basingstoke, Palgrave Macmillan: 77-100.

Reershemius, Gertrud (2007): Die Sprache der Auricher Juden. Wiesbaden: Harrassowitz.

Reershemius, Gertrud (2011): "Reconstructing the past? Low German and the creating of local identity in public language display". Journal of Multilingual and Multicultural Development 32/1: 33-54.

Reershemius, Gertrud (2020): "Semiotic Rural Landscapes and the Performance of Community in Villages: A Case Study from Low German-Speaking Northern Germany”. Linguistic Landscape 6/2: 128-154.

Reershemius, Gertrud (2021): “Transgressive Diskurse im ländlichen Raum. Eine Untersuchung der ,semiotic landscapes' in einer nordwestdeutschen Landgemeinde“. In: Martens, Heiko F./Ziegler, Evelyn (eds.): Linguistic Landscapes im deutschsprachigen Raum. Frankfurt a. M.: Lang: 141-161. 
Schroer, Markus (2009): „Bringing space back in': Zur Relevanz des Raums als soziologischer Kategorie“. In: Döring, Jörg/Thielmann, Tristan (eds.): Spatial Turn. Das Raumparadigma in den Kultur- und Sozialwissenschaften. Bielefeld, transcript: 125-148.

Schubert, Herbert (1999): „Urbaner öffentlicher Raum und Verhaltensregulierung“. disP - The Planning Review 35/136-137: 17-24. DOI: 10.1080/02513625.1999.10556695.

Scollon, Ron/Scollon, Suzie Wong (2003): Discourses in place. Language in the material world. London etc.: Routledge.

Schmitz, Ulrich/Ziegler, Evelyn (2016): Sichtbare Dialoge im öffentlichen Raum. In: Zeitschrift für germanistische Linguistik 44 (3): 469-502.

Siebel, Walter (2015): Die Kultur der Stadt. Berlin: Suhrkamp.

Sprick, Claus (2009): Hömma! Sprache im Ruhrgebiet. Mit einem grammatischen Anhang „Ruhrgebietsdeutsch in dreißig Regeln“ von Klaus Birkenhauer. 12., überarb. und erw. Aufl. Essen: Klartext.

Strohmeier, Peter/Bader, Silvia (2004): "Demographic Decline, Segregation, and Social Urban Renewal in Old Industrial Metropolitan Areas". German Journal of Urban Studies Vol. 44: $1-14$.

Tietz, Udo (2002): Die Grenzen des Wir. Eine Theorie der Gemeinschaft. Frankfurt a. M.: Suhrkamp.

Tophinke, Doris (2016): „In den tiefsten Winkeln unserer Betonwälder tanzten die Namen ein farbenfrohes Fest und wir tanzten mit bis in die Morgenstunden - Zur praktischen Kultur des Szene-Graffiti“. In: Deppermann, Arnulf/Feilke, Helmuth/Linke, Angelika (eds.): Kommunikative und sprachliche Praktiken. Berlin/Boston, de Gruyter: 405-430.

Tophinke, Doris/Ziegler, Evelyn (2019a): „Einleitung: Die Stadt als öffentlicher Kommunikationsraum“. Zeitschrift für germanistische Linguistik 47/2: 293-312.

Tophinke, Doris/Ziegler, Evelyn (2019b): „Hömma - Emblematischer Gebrauch von Dialektausdrücken“. Praxis Deutsch: 40-47.

Wachendorff, Irmi/Ziegler, Evelyn/Schmitz, Ulrich (2017): „Graffitiscape im Ruhrgebiet“. In: Lieb, Ludger/Müller, Stephan/Tophinke, Doris (eds.): Graffiti: Deutschsprachige Auf- und Inschriften in sprach- und literaturwissenschaftlicher Perspektive. Wien, Praesens: 154208.

Wikipedia: de.wikipedia.org. [05.10.2021].

Woods, Michael (2011): Rural. London/New York: Routledge.

Ziegler, Evelyn/Schmitz, Ulrich (im Druck): ,Semiotic-Landscape-Forschung: Daten- und Methodentriangulation im ,Metropolenzeichen'-Projekt". In: Beißwenger, Michael/Lemnitzer, Lothar/Müller-Spitzer, Carolin (eds.): Forschen in der Linguistik. Eine Methodeneinführung für das Germanistik-Studium. Stuttgart: UTB.

Ziegler, Evelyn et al. (2018): Metropolenzeichen. Atlas zur visuellen Mehrsprachigkeit der Metropole Ruhr. Duisburg: Universitätsverlag Rhein-Ruhr. 